\title{
The impact of residential combustion emissions on atmospheric aerosol, human health, and climate
}

\author{
E. W. Butt ${ }^{1}$, A. Rap $^{1}$, A. Schmidt ${ }^{1}$, C. E. Scott ${ }^{1}$, K. J. Pringle ${ }^{1}$, C. L. Reddington ${ }^{1}$, N. A. D. Richards ${ }^{1}$, \\ M. T. Woodhouse ${ }^{1,2}$, J. Ramirez-Villegas ${ }^{1,3}$, H. Yang $^{1}$, V. Vakkari ${ }^{4}$, E. A. Stone ${ }^{5}$, M. Rupakheti ${ }^{6}$, P. S. Praveen ${ }^{7}$, \\ P. G. van $\mathrm{Zyl}^{8}$, J. P. Beukes ${ }^{8}$, M. Josipovic ${ }^{8}$, E. J. S. Mitchell ${ }^{9}$, S. M. Sallu ${ }^{10}$, P. M. Forster ${ }^{1}$, and D. V. Spracklen ${ }^{1}$ \\ ${ }^{1}$ Institute for Climate and Atmospheric Science, School of Earth and Environment, University of Leeds, Leeds, UK \\ ${ }^{2}$ CSIRO Oceans and Atmosphere, Aspendale, Victoria, Australia \\ ${ }^{3}$ International Centre for Tropical Agriculture, Cali, Colombia \\ ${ }^{4}$ Finnish Meteorological Institute, Helsinki, Finland \\ ${ }^{5}$ Department of Chemistry, University of Iowa, Iowa City, Iowa 52242, USA \\ ${ }^{6}$ Institute for Advanced Sustainability Studies, Potsdam, Germany \\ ${ }^{7}$ International Centre for Integrated Mountain Development, Kathmandu, Nepal \\ ${ }^{8}$ North-West University, Unit for Environmental Sciences and Management, 2520 Potchefstroom, South Africa \\ ${ }^{9}$ Energy Research Institute, School of Chemical and Process Engineering, University of Leeds, Leeds, UK \\ ${ }^{10}$ Sustainability Research Institute, School of Earth and Environment, University of Leeds, Leeds, UK
}

Correspondence to: E. W. Butt (e.butt@leeds.ac.uk)

Received: 29 May 2015 - Published in Atmos. Chem. Phys. Discuss.: 29 July 2015

Revised: 10 November 2015 - Accepted: 6 January 2016 - Published: 26 January 2016

\begin{abstract}
Combustion of fuels in the residential sector for cooking and heating results in the emission of aerosol and aerosol precursors impacting air quality, human health, and climate. Residential emissions are dominated by the combustion of solid fuels. We use a global aerosol microphysics model to simulate the impact of residential fuel combustion on atmospheric aerosol for the year 2000. The model underestimates black carbon (BC) and organic carbon (OC) mass concentrations observed over Asia, Eastern Europe, and Africa, with better prediction when carbonaceous emissions from the residential sector are doubled. Observed seasonal variability of $\mathrm{BC}$ and $\mathrm{OC}$ concentrations are better simulated when residential emissions include a seasonal cycle. The largest contributions of residential emissions to annual surface mean particulate matter $\left(\mathrm{PM}_{2.5}\right)$ concentrations are simulated for East Asia, South Asia, and Eastern Europe. We use a concentration response function to estimate the human health impact due to long-term exposure to ambient $\mathrm{PM}_{2.5}$ from residential emissions. We estimate global annual excess adult ( $>30$ years of age) premature mortality (due to both cardiopulmonary disease and lung cancer) to be 308000 (113 300-497000, 5th to 95th percentile uncertainty
\end{abstract}

range) for monthly varying residential emissions and 517000 (192 000-827 000) when residential carbonaceous emissions are doubled. Mortality due to residential emissions is greatest in Asia, with China and India accounting for $50 \%$ of simulated global excess mortality. Using an offline radiative transfer model we estimate that residential emissions exert a global annual mean direct radiative effect between -66 and $+21 \mathrm{~mW} \mathrm{~m}^{-2}$, with sensitivity to the residential emission flux and the assumed ratio of $\mathrm{BC}, \mathrm{OC}$, and $\mathrm{SO}_{2}$ emissions. Residential emissions exert a global annual mean first aerosol indirect effect of between -52 and $-16 \mathrm{~mW} \mathrm{~m}^{-2}$, which is sensitive to the assumed size distribution of carbonaceous emissions. Overall, our results demonstrate that reducing residential combustion emissions would have substantial benefits for human health through reductions in ambient $\mathrm{PM}_{2.5}$ concentrations. 


\section{Introduction}

Combustion of fuels within the household for cooking and heating, known as residential fuel combustion, is an important source of aerosol emissions with impacts on air quality and climate (Ramanathan and Carmichael, 2008; Lim et al., 2012). In most regions, residential emissions are dominated by the combustion of residential solid fuels (RSFs, see Table A1 for list of acronyms used in the study) such as wood, charcoal, agricultural residue, animal waste, and coal. Nearly 3 billion people, mostly in the developing world, depend on the combustion of RSFs as their primary energy source (Bonjour et al., 2013). RSFs are usually burnt in simple stoves or open fires with low combustion efficiencies, resulting in substantial emissions of aerosol. It has been suggested that reducing RSF emissions would be a fast way to mitigate climate and improve air quality (UNEP, 2011), but the climate impacts of RSF emissions are uncertain (Bond et al., 2013). Whilst it is clear that RSF combustion has substantial adverse impacts on human health through poor indoor air quality, there have been few studies quantifying the impacts on outdoor air quality and human health. Here, we use a global aerosol microphysics model to estimate the impacts of residential fuel combustion on atmospheric aerosol, climate, and human health.

Residential emissions due to the small-scale combustion of biomass and fossil fuels used for cooking, heating, lighting, and auxiliary engines include black carbon (BC), particulate organic matter (POM), primary inorganic sulfate, and gas-phase $\mathrm{SO}_{2}$. Residential emissions contribute substantially to the global aerosol burden, accounting for $25 \%$ of global energy-related BC emissions (Bond et al., 2013). In China and India, residential emissions are even more important, accounting for $50-60 \%$ of BC and $60-80 \%$ of organic carbon (OC) emissions (Cao et al., 2006; Klimont et al., 2009; Lei et al., 2011). The combustion of residential fuels also emit volatile and semi-volatile organic compounds that lead to the production of secondary organic aerosols via atmospheric oxidation. Residential emissions are dominated by emissions from RSFs in many regions, due to poor combustion efficiency of RSFs and extensive use across the developing world (Bond et al., 2013). In China, residential combustion of both biomass (referred to as "biofuel") and coal is important, whereas across other parts of Asia and Africa residential combustion of biofuel is dominant ( $\mathrm{Lu}$ et al., 2011; Bond et al., 2013).

Estimates of residential emissions are typically "bottomup", combining information on fuel consumption rates with laboratory or field emission factors. Obtaining reliable estimates of residential fuel use is difficult because these fuels are often collected by consumers and are not centrally recorded (Bond et al., 2013). Emission factors are hugely variable, depending on the type, size, and moisture content of fuel, as well as stove design, operation, and combustion conditions (Roden et al., 2006, 2009; Li et al., 2009; Shen et al., 2010). As a result, uncertainty in residential emissions may be as large as a factor 2 or more (Bond et al., 2004). There is a range of evidence that residential emissions may be underestimated. Firstly, emission factors for RSF combustion derived from laboratory experiments are often less than those derived under ambient conditions (Roden et al., 2009). Secondly, models typically underestimate observed aerosol absorption optical depth, BC, and OC over regions associated with large RSF emissions such as in South and East Asia (Park et al., 2005; Koch et al., 2009; Ganguly et al., 2009; Menon et al., 2010; Nair et al., 2012; Fu et al., 2012; Moorthy et al., 2013; Bond et al., 2013; Pan et al., 2015). A further complication is that residential emissions, particularly from residential heating, also exhibit seasonal variability (Aunan et al., 2009; Stohl et al., 2013), but this is rarely implemented within global modelling studies.

Atmospheric aerosols interact with the Earth's radiation budget directly through the scattering and absorption of solar radiation (direct radiative effect - DRE - or aerosolradiation interactions) and indirectly by modifying the microphysical properties of clouds (aerosol indirect effect AIE - or aerosol-cloud interactions) (Forster et al., 2007; Boucher et al., 2013). The interaction of aerosol with radiation and clouds depends on properties of the aerosol, including mass concentration, size distribution, chemical composition, and mixing state (Boucher et al., 2013). BC is strongly absorbing at visible and infrared wavelengths, exerting a positive DRE5. BC particles coated with a non-absorbing shell have greater absorption compared to a fresh $\mathrm{BC}$ core due to a lensing effect (Fuller et al., 1999; Jacobson, 2001). More recent studies have shown that a fraction of organic aerosol can absorb light (Kirchstetter et al., 2004; Chen and Bond, 2010; Arola et al., 2011), with the light absorbing fraction termed "brown carbon". The net DRE of residential combustion emissions is a complex combination of these warming and cooling effects.

Aerosol also impacts climate through altering the properties of clouds. The cloud albedo or first AIE is the radiative effect due to a change in cloud droplet number concentration (CDNC), assuming a fixed cloud water content. The change in CDNC is governed by the number concentration of aerosols that are able to act as cloud condensation nuclei $(\mathrm{CCN})$, which is determined by aerosol size and chemical composition (Penner et al., 2001; Dusek et al., 2006). Modelling studies have shown the importance of carbonaceous combustion aerosols to global CCN concentrations (Pierce et al., 2007; Spracklen et al., 2011a) and modification of cloud properties (Bauer et al., 2010; Jacobson, 2010). However, there is considerable variability in the size of particles emitted by combustion sources including those from residential sources (Venkataraman and Rao, 2001; Shen et al., 2010; Pagels et al., 2013; Bond et al., 2006) that will impact simulated CCN concentrations (Pierce et al., 2007, 2009; Reddington et al., 2011; Spracklen et al., 2011a; Kodros et al., 2015) and AIE (Bauer et al., 2010; Spracklen et 
al., 2011a; Kodros et al., 2015). Aerosols can further alter cloud properties through the second aerosol indirect effect and through semi-direct effects (Koch and Del Genio, 2010).

The net radiative effect (RE) of residential emissions depends on the fuel and combustion process (Bond et al., 2013). Carbonaceous emissions from residential biofuel exhibit higher POM: $\mathrm{BC}$ mass ratios compared to residential coal, which emits more $\mathrm{BC}$ and sulfur (Bond et al., 2013). Aunan et al. (2009) found that despite large BC emissions over Asia, RSF combustion emissions exerted a small net negative DRE because of co-emitted scattering aerosols; however, this study did not include aerosol-cloud effects. Jacobson (2010) reported increased cloud cover and depth from biofuel aerosol and gases as well as a net positive RE. In contrast, Bauer et al. (2010) found the negative AIE from residential biofuel combustion to be 3 times greater than the positive DRE, resulting in a negative net RE. Unger et al. (2010) used a mass-only aerosol model to calculate a positive AIE due to the residential sector. The review of Bond et al. (2013) identified a net negative RE (DRE and AIE) for biofuel with large uncertainty but a slight net positive RE (with low certainty) from residential coal (Bond et al., 2013). However, a recent detailed global modelling study found that the climate effects of residential biofuel combustion aerosol are largely unconstrained because of uncertainties in emission mass flux, emitted size distribution, optical mixing state, and ratio of BC to POM (Kodros et al., 2015)

In addition to impacting climate, aerosol from residential fuel combustion degrades air quality with adverse implications for human health. Epidemiologic research has confirmed a strong link between exposure to particulate matter (PM) and adverse health effects, including premature mortality (Pope III and Dockery, 2006; Brook et al., 2010). Exposure to $\mathrm{PM}_{2.5}$ (PM with an aerodynamic dry diameter of $<2.5 \mu \mathrm{m}$ ) is thought to be particularly harmful to human health (Pope III and Dockery, 2006; Schlesinger et al., 2006). Household air pollution, mostly from RSF combustion (Smith et al., 2014) in low and middle income countries, is estimated to cause 4.3 million deaths annually (WHO, 2014a), making it one of the leading risk factors for global disease burden (Lim et al., 2012). Global estimates of premature mortality attributable to ambient (outdoor) air pollution range from 0.8 million to 3.7 million deaths per year, most of which occur in Asia (Cohen et al., 2005; Anenberg et al., 2010; WHO, 2014b). These estimates rely on $\mathrm{PM}_{2.5}$ concentrations from coarse global models with mean spatial resolutions of $\sim 200 \mathrm{~km}$. At these resolutions, human health estimates are likely underestimated at urban and semiurban scales. Emission inventories highlight residential combustion as one of the most important contributors to ambient $\mathrm{PM}_{2.5}$, accounting for $55 \%$ in Europe (EEA, 2014) and $33 \%$ in China (Lei et al., 2011). However, while previous studies have estimated the human health impacts from ambient air pollution due to fossil fuel combustion (Anenberg et al., 2010), open biomass burning (Johnston et al., 2012;
Marlier et al., 2013), and wind-blown dust (Giannadaki et al., 2014), fewer studies have quantified the impact of residential combustion on ambient quality and human health. Lim et al. (2012) estimated that $16 \%$ of the global burden of ambient $\mathrm{PM}_{2.5}$ was due to RSF sources but did not estimate premature mortality. Another study concluded that ambient $\mathrm{PM}_{2.5}$ from cooking was responsible for 370000 deaths in 2010 (Chafe et al., 2014), but it did not include residential heating emissions, which will cause additional adverse impacts on human health (Johnston et al., 2013; Allen et al., 2013; Y. Chen et al., 2013).

Here we use a global aerosol microphysics model to make an integrated assessment of the impact of residential emissions on atmospheric aerosol, radiative effect, and human health. We used a radiative transfer model to calculate the DRE and first AIE due to residential emissions. To improve our understanding of the health impacts associated with these emissions, we combined simulated $\mathrm{PM}_{2.5}$ concentrations with concentration-response functions from the epidemiological literature to estimate excess premature mortality.

\section{Methods}

\subsection{Model description}

We used the GLOMAP global aerosol microphysics model (Spracklen et al., 2005a), which is an extension to the TOMCAT 3-D global chemical transport model (Chipperfield, 2006). We used the modal version of the model, GLOMAPmode (Mann et al., 2010), where aerosol mass and number concentrations are carried in seven log-normal size modes: four hydrophilic (nucleation, Aitken, accumulation, and coarse) and three non-hydrophilic (Aitken, accumulation, and coarse) modes. The model includes size-resolved aerosol processes including primary emissions, secondary particle formation, particle growth through coagulation, condensation, and cloud-processing and removal by dry deposition, in-cloud, and below-cloud scavenging. The model treats particle formation from both binary homogenous nucleation (BHN) of $\mathrm{H}_{2} \mathrm{SO}_{4}-\mathrm{H}_{2} \mathrm{O}$ (Kulmala et al., 1998) and an empirical mechanism to simulate nucleation within the model boundary layer or boundary layer nucleation (BLN). The formation rate of $1 \mathrm{~nm}$ clusters ( $\mathrm{J} 1$ ) within the $\mathrm{BL}$ is proportional to the gas-phase $\mathrm{H}_{2} \mathrm{SO}_{4}$ concentration $\left(\left[\mathrm{H}_{2} \mathrm{SO}_{4}\right]\right)$ to the power of 1 (Sihto et al., 2006; Kulmala et al., 2006) according to $\mathrm{J} 1=A\left[\mathrm{H}_{2} \mathrm{SO}_{4}\right]$, where $A$ is the nucleation rate coefficient of $2 \times 10^{-6} \mathrm{~s}^{-1}$ (Sihto et al., 2006). GLOMAPmode simulates multi-component aerosol and treats the following components: sulfate, dust, BC, POM, and sea salt. Primary carbonaceous combustion particles (BC and $\mathrm{POM}$ ) are emitted as a non-hydrophilic distribution (Aitken insoluble mode). Dust is emitted into the insoluble accumulation and coarse modes. Non-hydrophilic particles are transferred 
into hydrophilic particles through coagulation and condensation processes. The model uses a horizontal resolution of $2.8^{\circ}$ by $2.8^{\circ}$ and 31 vertical levels between the surface and $10 \mathrm{hPa}$. Large-scale transport and meteorology is specified at $6 \mathrm{~h}$ intervals from the European Centre for Medium-Range Weather Forecasts (ECMWF) analyses interpolated to model timestep. All model simulations are for the year 2000, completed after a 3-month model spin up. Oxidants of $\mathrm{OH}, \mathrm{O}_{3}$, $\mathrm{H}_{2} \mathrm{O}_{2}, \mathrm{NO}_{3}$, and $\mathrm{HO}_{2}$ are specified using $6 \mathrm{~h}$ mean offline concentrations from a TOMCAT simulation with detailed tropospheric chemistry (Arnold et al., 2005).

\subsection{Emissions}

The model uses gas-phase $\mathrm{SO}_{2}$ emissions for both continuous (Andres and Kasgnoc, 1998) and explosive (Halmer et al., 2002) volcanic eruptions. Open biomass burning emissions are from the Global Fire Emission Database (van der Werf et al., 2004). Oceanic dimethyl-sulfide (DMS) emissions are calculated using an ocean surface DMS concentration database (Kettle and Andreae, 2000) combined with a sea-air exchange parameterization (Nightingale et al., 2000). Emissions of sea salt were calculated using the scheme of Gong (2003). Biogenic emissions of terpenes are taken from the Global Emissions Inventory Activity database and are based on Guenther et al. (1995). Daily-varying dust emission fluxes are provided by AeroCom (Dentener et al., 2006).

Annual mean anthropogenic emissions of gas-phase $\mathrm{SO}_{2}$ and carbonaceous aerosol for the year 2000 are taken from the Atmospheric Chemistry and Climate Model Intercomparison Project (ACCMIP) (Lamarque et al., 2010). This data set includes emissions from energy production and distribution, industry, land transport, maritime transport, residential and commercial, and agricultural waste burning on fields. To test the sensitivity to anthropogenic emissions, we completed sensitivity studies (see Sect. 2.6) using anthropogenic emissions from the MACCity (MACC/CityZEN projects) emission data set for the year 2000 (Granier et al., 2011). MACCity emissions are derived from ACCMIP and apply a monthly varying seasonal cycle for anthropogenic emissions (Granier et al., 2011). In both emissions data sets, anthropogenic carbonaceous emissions are based on the Speciated Particulate Emissions Wizard (SPEW) inventory (Bond et al., 2007). In GLOMAP, anthropogenic carbonaceous emissions are added to the lowest model layer, while open biomass burning emissions are emitted between the surface and $6 \mathrm{~km}$ (Dentener et al., 2006).

We isolate the impact of residential fuel combustion through simulations where we switch off emissions from the "residential and commercial" sector. The term "residential" includes emissions from household activities, while "commercial" refers to emissions from commercial business activities (excluding agricultural activities). Both residential and commercial activities use similar fuels for similar purposes, but because emissions are dominated by residential activi- ties, we refer to the "residential and commercial" sector collectively as the "residential" sector. Residential fuels used in small-scale combustion for cooking, heating, lighting, and auxiliary engines, consist of many different types such as RSFs (biomass/biofuel and coal) and hydrocarbon-based fuels including kerosene, liquefied petroleum gas, gasoline, and diesel. The ACCMIP and MACCity residential data sets do not allow us to isolate the impacts of different RSFs separately from other residential hydrocarbon-based fuels, but according to the results from the Greenhouse Gas and Air Pollution Interactions and Synergies (GAINS) model, typically $\geq 90 \%$ of PM emissions can be attributed to RSFs within most regions, of which a large proportion is from biomass sources. Compared with residential hydrocarbon-based fuels, RSFs typically burn at lower combustion efficiencies, resulting in substantially higher aerosol emissions (Venkataraman et al., 2005). Residential kerosene wick lamps can produce substantial emissions (Lam et al., 2012); however, these are not included in the ACCMIP and MACCity data sets. Residential biofuel and coal emissions from ACCMIP and MACCity differ to previous global emission inventories (Bond et al., 2004, 2007) through the incorporation of updated emissions factors from field measurements (Roden et al., 2006, 2009; Johnson et al., 2008) and laboratory experiments for biofuel sources in India (Venkataraman et al., 2005; Parashar et al., 2005) and residential coal sources in China (Chen et al., 2005, 2006; Zhi et al., 2008). In both the ACCMIP and MACCity emission data sets, global emissions for the residential and commercial sectors are $\mathrm{BC}\left(\sim 1.9 \mathrm{Tg} \mathrm{yr}^{-1}\right)$, POM $\left(\sim 11.0 \mathrm{Tg} \mathrm{POM} \mathrm{yr}^{-1}\right)$, and $\mathrm{SO}_{2}\left(\sim 8.3 \mathrm{Tg} \mathrm{SO}_{2} \mathrm{yr}^{-1}\right)$.

Figure 1 shows the spatial distribution of $\mathrm{BC}, \mathrm{POM}$, and $\mathrm{SO}_{2}$ emissions from the residential sector in the ACCMIP data set (Lamarque et al., 2010). Residential emissions are greatest over densely populated regions of Africa and Asia where infrastructure and income do not allow access to clean sources of residential energy. The dominant fuel type varies spatially resulting in distinct patterns in pollutant emission ratios (Fig. 1d-e). Residential emissions are dominated by biofuel (biomass) combustion in sub-Saharan Africa, South Asia, and parts of Southeast Asia and characterised by low $\mathrm{BC}: \mathrm{POM}$ and high $\mathrm{BC}: \mathrm{SO}_{2}$ ratios. Residential coal combustion is more important in parts of Eastern Europe, the Russian Federation, and East Asia, characterised by higher $\mathrm{BC}: \mathrm{POM}$ and lower $\mathrm{BC}: \mathrm{SO}_{2}$ ratios. In the ACCMIP and MACCity data sets, residential sources account for $38 \%$ of global total anthropogenic BC and $61 \%$ of total global anthropogenic POM emissions. The regional contribution of residential emissions can be even greater (Fig. 1f). For China, residential emissions represent $40 \%$ of anthropogenic BC and $60 \%$ of anthropogenic POM emissions. In India, residential emissions represent $63 \%$ of anthropogenic $\mathrm{BC}$ and $78 \%$ of anthropogenic POM emissions.

We assume primary particles from combustion sources are emitted with a fixed log-normal size distribution with a specified geometric mean diameter $(D)$ and standard de- 
(a)

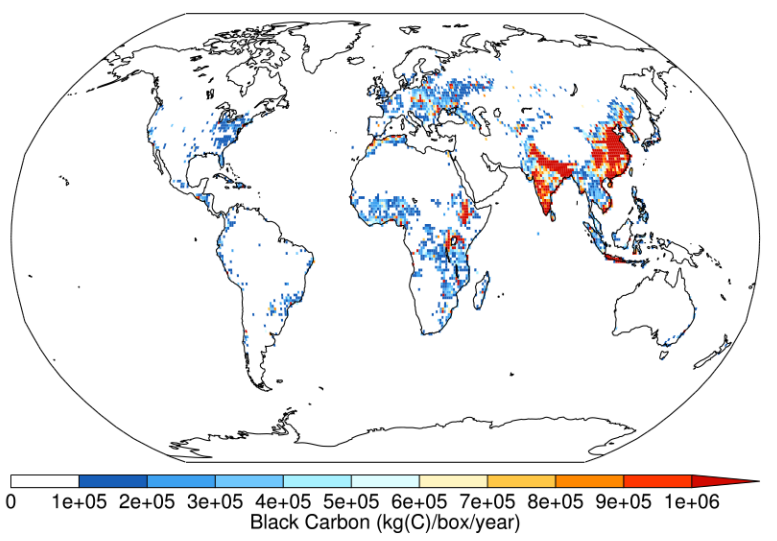

(c)

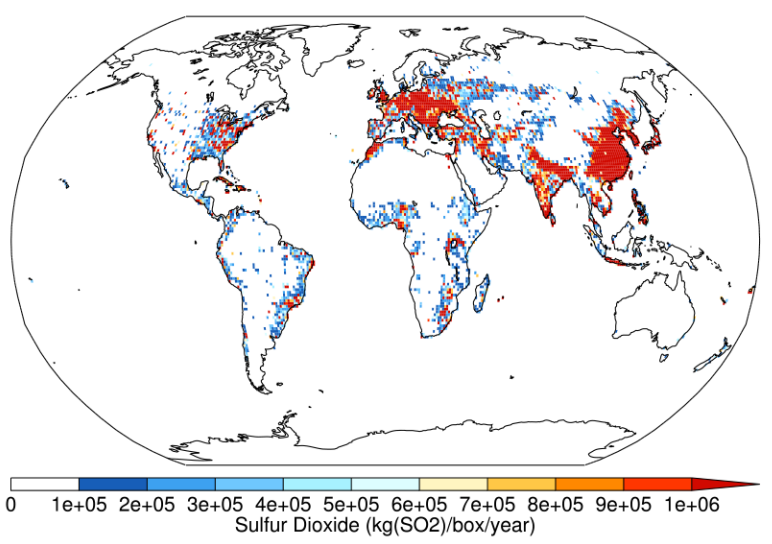

(e)

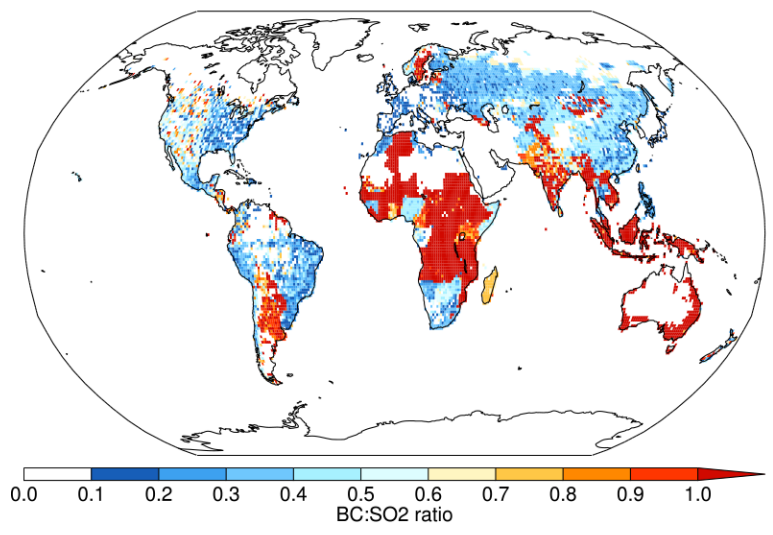

(b)

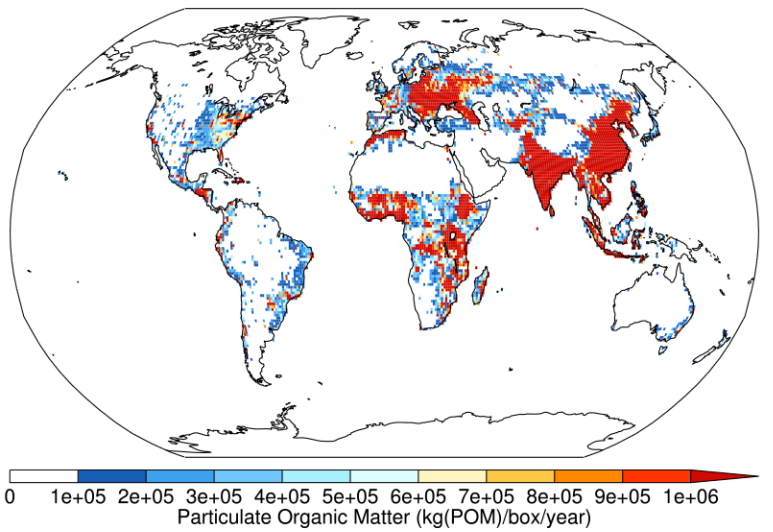

(d)

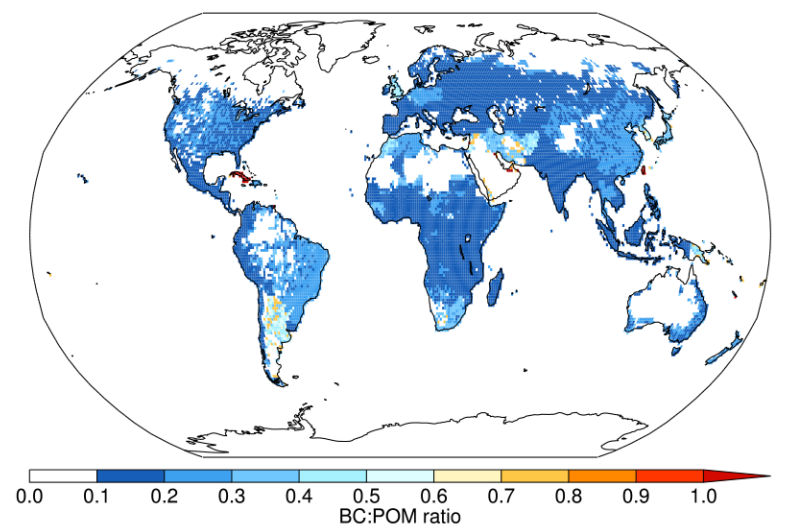

(f)

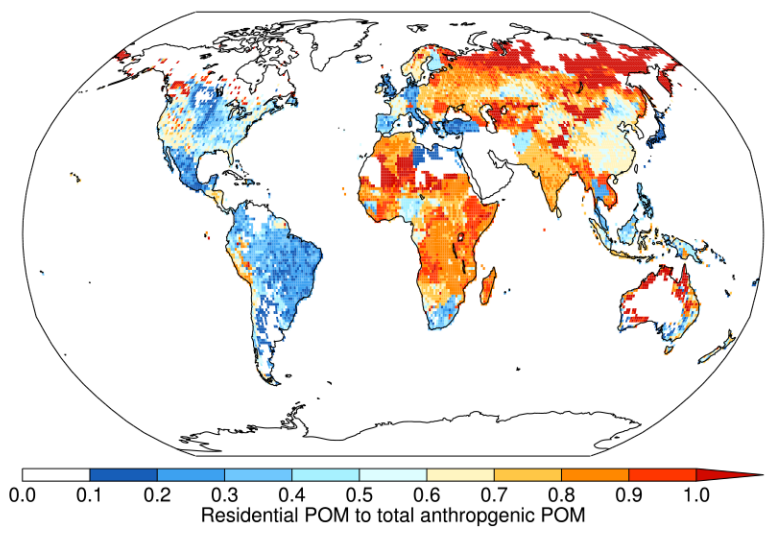

Figure 1. Annual residential emissions from the ACCMIP emission data set for $\mathrm{BC}(\mathbf{a}), \mathrm{POM}(\mathbf{b}), \mathrm{SO}_{2}$ (c), $\mathrm{BC}$ : $\mathrm{POM}$ ratio (d), $\mathrm{BC}: \mathrm{SO}_{2}$ ratio (e), and residential POM to total anthropogenic POM (f).

viation $(\sigma)$. Assumptions regarding $D$ and $\sigma$ for each experiment are detailed in the footnotes of Table 2. This assumption accounts for both the size of primary particles at the point of emission and the sub-grid-scale dynamical processes that contribute to changes in particle size and number concentrations at short timescales after emission (Pierce and Adams, 2009; Reddington et al., 2011). Subsequent aging and growth of the particles are determined by microphysical processes such as coagulation, condensation, and cloud processing simulated by the model. We assume that $2.5 \%$ of $\mathrm{SO}_{2}$ from anthropogenic and volcanic sources is emitted as primary sulfate particles. 


\subsection{In situ measurements}

To evaluate our model, we synthesised in situ measurements of $\mathrm{BC}, \mathrm{OC}$, and $\mathrm{PM}_{2.5}$ concentrations, aerosol number size distribution, and estimates of the contribution of biomass derived $\mathrm{BC}$ from ${ }^{14} \mathrm{C}$ analysis. GLOMAP has been evaluated for locations in North America (Mann et al., 2010; Spracklen et al., 2011a), the Arctic (Browse et al., 2012; Reddington et al., 2013), and Europe (Schmidt et al., 2011). Here, we focus our evaluation at locations that may be strongly influenced by residential emissions (Fig. 1) and where the model has not been previously evaluated. We focus on rural and background locations because these are more appropriate for comparison to global models with coarse spatial resolutions.

Figure 2 shows the locations of observations used in this study. Information on the measurements for each location is reported in Table 1. Note that the coloured geographical regions in Fig. 2 are only used to distinguish differences in mortality across different regions (see Sect. 3.3). The technique and instruments used to measure $\mathrm{BC}$ and $\mathrm{OC}$ vary across the different sites (see Table 1). Thermal-optical techniques measure elemental carbon (EC) whereas optical techniques measure BC. Previous studies have documented systematic differences between these techniques but concluded that measurement uncertainties are generally larger than the differences between the measurement techniques (Bond et al., 2004, 2007). We therefore treat different measurement techniques identically and consider $\mathrm{EC}$ and $\mathrm{BC}$ to be equivalent. For sites in Eastern Europe, we used BC and OC mass concentrations from the Czech Republic and Slovenia (Table 1). For sites in South Africa, we used $\mathrm{PM}_{2.5}$ and $\mathrm{BC}$ mass and aerosol number size distribution (Vakkari et al., 2013). For sites in South Asia, we used BC mass from the Integrated Campaign for Aerosols gases and Radiation Budget (ICARB) field campaign at eight locations across the Indian mainland and islands (Moorthy et al., 2013). For South Asian sites, we also used $\mathrm{PM}_{2.5}, \mathrm{EC}$, and OC mass, aerosol number size distribution from the island of Hanimaadhoo in the Maldives (Stone et al., 2007), and EC and OC measurements from Godavari in Nepal (Stone et al., 2010). For sites in East Asia, we used EC and OC mass data compiled by $\mathrm{Fu}$ et al. (2012) for two background (Qu et al., 2008) and seven rural sites (Zhang et al., 2008; Han et al., 2008) in China, while measurements from Gosan, South Korea, were taken from Stone et al. (2011). Few long-term observations of $\mathrm{CCN}$ are available, so instead we use the number concentration of particles greater than $50 \mathrm{~nm}$ dry diameter $\left(N_{50}\right)$ and $100 \mathrm{~nm}\left(N_{100}\right)$ as a proxy for $\mathrm{CCN}$ number concentrations. We calculated $N_{50}$ and $N_{100}$ concentrations from aerosol number size distribution measurements at Hanimaadhoo, Botsalano, Marikana, and Welgegund (see Table 1). We note this approach does not account for the impact of particle composition on $\mathrm{CCN}$ activity.

We also use information on BC fossil and non-fossil fractions as obtained from three separate source apportionment

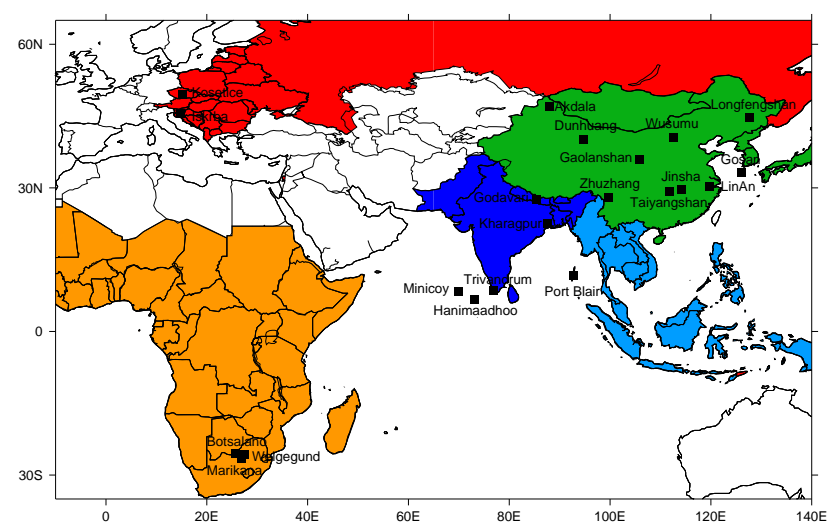

Figure 2. Locations of aerosol measurements used in this study and geographical regions of Eastern Europe and the Russian Federation (red), Africa (orange), South Asia (dark blue), Southeast Asia (light blue), and East Asia (green). Note that geographical regions are only used to distinguish difference in mortality across different regions (see Sect. 3.3).

studies (Gustafsson et al., 2009; Sheesley et al., 2012; Bosch et al., 2014) that use ${ }^{14} \mathrm{C}$ analysis of carbonaceous aerosol taken at Hanimaadhoo in the Indian Ocean. This technique determines the fossil and non-fossil fractions of carbonaceous aerosol, since ${ }^{14} \mathrm{C}$ is depleted in fossil fuel aerosol (half-life 5730 years), whereas non-fossil aerosol (e.g. biofuel, open biomass burning, and biogenic emissions) shows a contemporary ${ }^{14} \mathrm{C}$ content. As previously mentioned, residential emissions consist of a mixture of both fossil and nonfossil sources, with a greater proportion coming from the former. To make distinctions on the fossil versus non-fossil fraction of residential BC emissions, we make assumptions based on information from other emission inventories and models over the South Asian region (see Sect. 3.2 for more details).

\subsection{Calculating health effects}

We calculate annual excess premature mortality from exposure to ambient $\mathrm{PM}_{2.5}$ using concentration response functions (CRFs) from the epidemiological literature that relate changes in $\mathrm{PM}_{2.5}$ concentrations to the relative risk (RR) of disease. CRFs are uncertain and have been previously based on the relationship between $\mathrm{RR}$ and $\mathrm{PM}_{2.5}$ concentrations using either a log-linear model (Ostro, 2004) or a linear model (Cohen et al., 2004). These CRFs were based on the American Cancer Society Prevention cohort study, where observed annual mean $\mathrm{PM}_{2.5}$ concentrations were typically below $30 \mathrm{~g} \mathrm{~m}^{-3}$. The log-linear model was recommended by the WHO for use in ambient air pollution burden of disease estimates at the national level (Ostro, 2004) due to the concern that linear models would produce unrealistically large RR estimates when extrapolated to higher $\mathrm{PM}_{2.5}$ concentrations above that of $30 \mu \mathrm{g} \mathrm{m}^{-3}$. The log-linear models have been used in various modelling studies (Anenberg et al., 


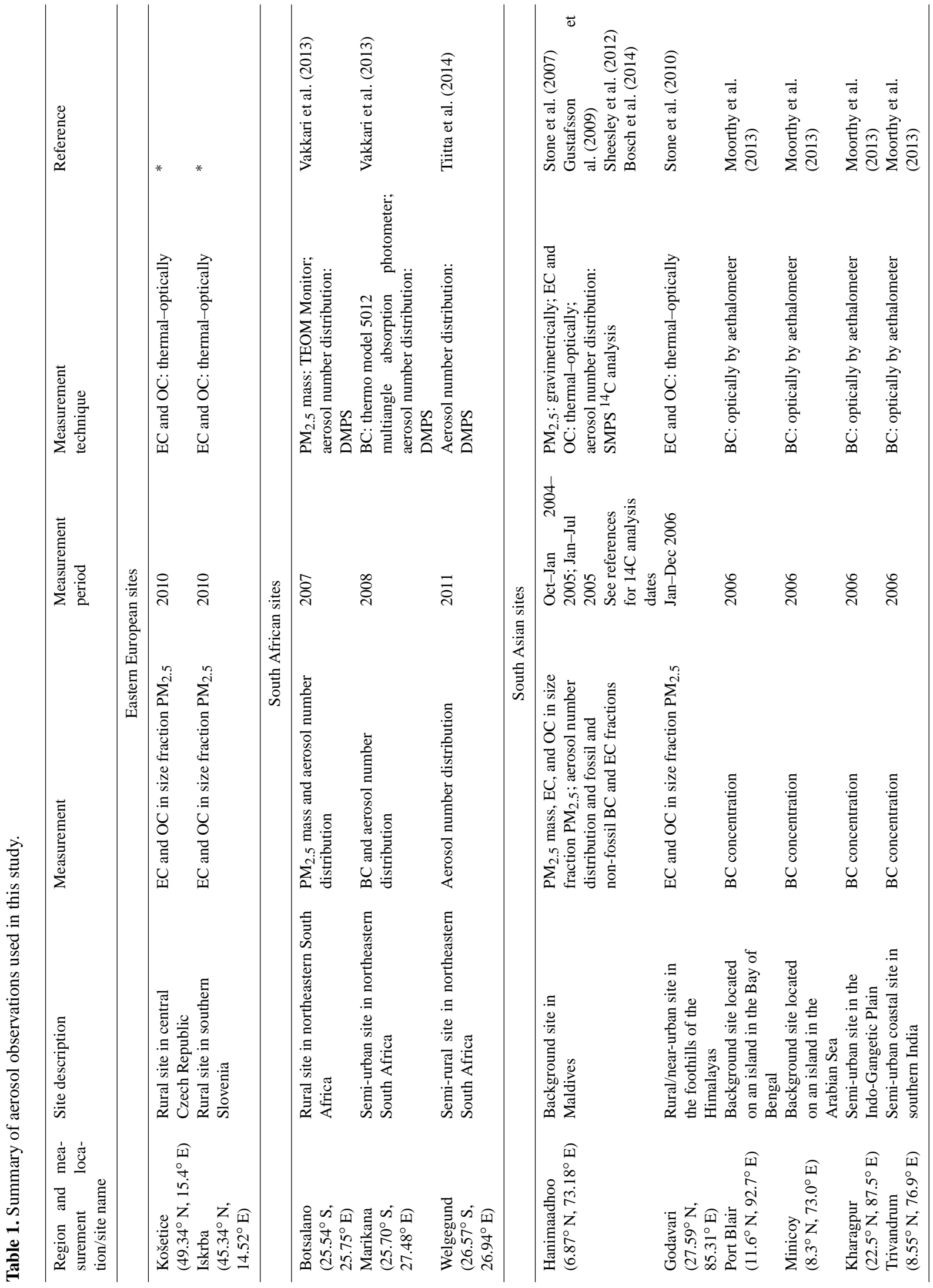




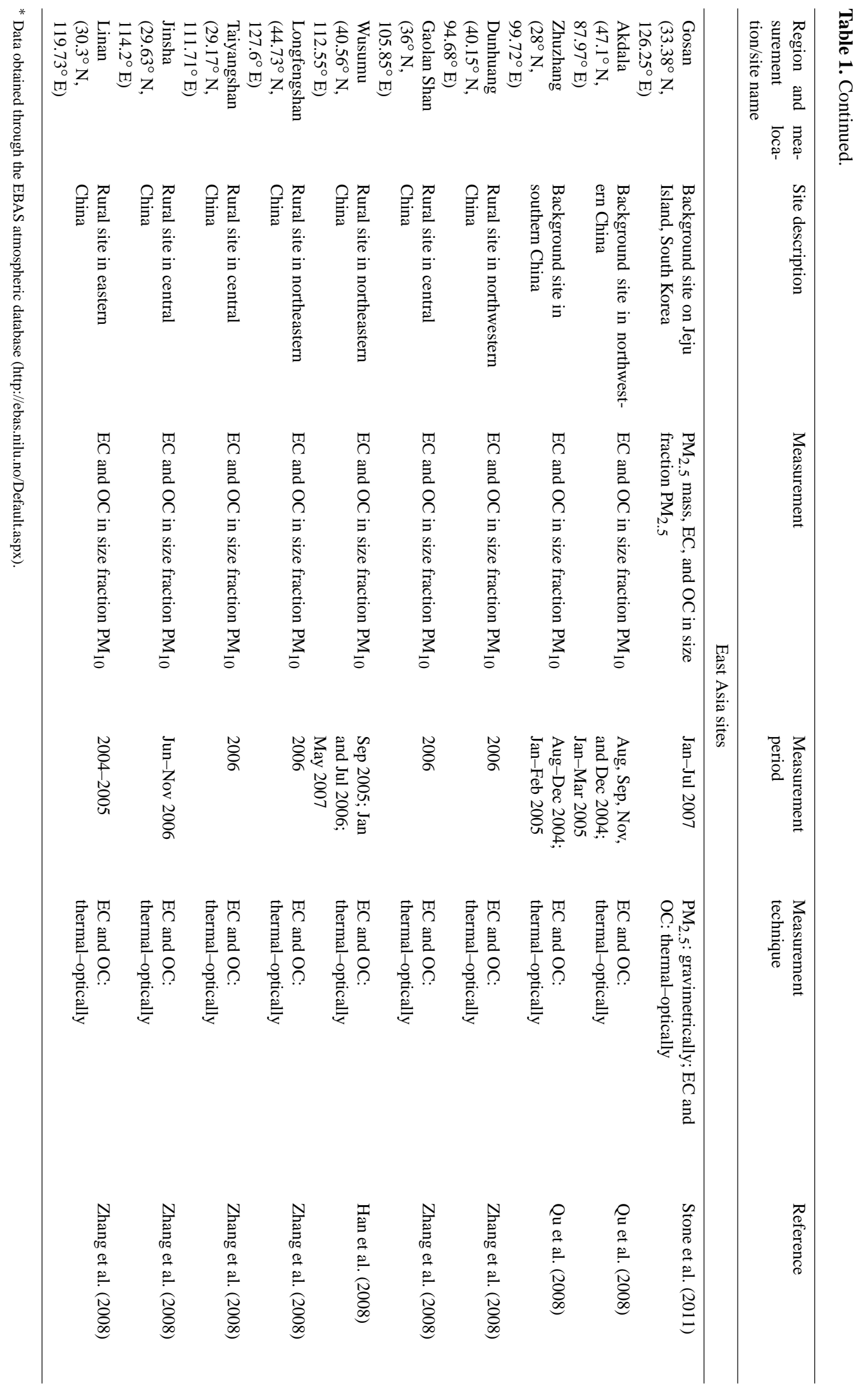


2010; Schmidt et al., 2011; Partanen et al., 2013; Reddington et al., 2015). More recent models have been proposed to relate disease burden to different combustion sources in order to capture RR over a larger range of $\mathrm{PM}_{2.5}$ concentrations up to $300 \mu \mathrm{g} \mathrm{m}^{-3}$ (Burnett et al., 2014). However, given that we use a global model with relatively coarse spatial resolution where $\mathrm{PM}_{2.5}$ concentrations very rarely exceed $100 \mu \mathrm{g} \mathrm{m}^{-3}$, we employ the log-linear model of Ostro (2004). We calculate RR for cardiopulmonary diseases and lung cancer following Ostro (2004):

$\mathrm{RR}=\left[\frac{\left(\mathrm{PM}_{2.5, \text { control }}+1\right)}{\left(\mathrm{PM}_{2.5, \mathrm{R} \_ \text {off }}+1\right)}\right]^{\beta}$,

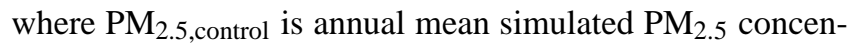
trations of the control experiments and $\mathrm{PM}_{2.5, \mathrm{R} \_ \text {off }}$ is a perturbed experiment where residential emissions have been removed. The cause-specific coefficient $(\beta)$ is an empirical parameter with separate values for lung cancer $(0.23218$, $95 \%$ confidence interval of $0.08563-0.37873)$ and cardiopulmonary diseases $(0.15515,95 \%$ confidence interval of $0.05624-0.2541$ ). To calculate the disease burden attributable to the RR, known as the attributable fraction (AF), we follow Ostro (2004):

$\mathrm{AF}=(\mathrm{RR}-1) / \mathrm{RR}$.

To calculate the number of excess premature mortality in adults over 30 years of age, we apply AF to the total number of recorded deaths from the diseases of interest:

$\Delta M=\mathrm{AF} \times M_{0} \times P_{30+}$,

where $M_{0}$ is the baseline mortality rate for each disease risk and $P_{30+}$ is the exposed population over 30 years of age. We only calculate premature mortality for persons over the age of 30 years because this fraction of the population is more susceptible to cardiopulmonary disease and lung cancer. We use country-specific baseline mortality rates from the WHO "The global burden of disease: 2004 update" (Mathers et al., 2008) for the year 2004 and human population data from the Gridded World Population (GWP, version 3) project (SEDAC, 2004) for the year 2000.

\subsection{Calculating radiative effects}

We quantified the DRE and first AIE of residential emissions using an offline radiative transfer model (Edwards and Slingo, 1996). With nine radiation bands in the longwave (LW) and six bands in the shortwave (SW). We use a monthly mean climatology of water vapour, temperature, and ozone based on ECMWF reanalysis data, together with surface albedo and cloud fields from the International Satellite Cloud Climatology Project (ISCCP-D2) (Rossow and Schiffer, 1999) for the year 2000.

Following the methodology described in Rap et al. (2013) and Scott et al. (2014), we estimate the DRE using the radiative transfer model to calculate the difference in net $(\mathrm{SW}+\mathrm{LW})$ top-of-atmosphere (TOA) all-sky radiative flux between model simulations with and without residential emissions. A refractive index is calculated for each individual mode separately, as the volume-weighted mean of the refractive indices for the individual components (including water) present (given at $550 \mathrm{~nm}$ in Table A1 of Bellouin et al., 2011). Coefficients for absorption and scattering, and asymmetry parameters, are then obtained from look-up tables containing all realistic combinations of refractive index and Mie parameter (particle radius normalised to the wavelength of radiation), as described by Bellouin et al. (2013). The assumption that $\mathrm{BC}$ is internally or homogeneously mixed with scattering species is unrealistic, providing an upper bound for DRE (Jacobson, 2001; Kodros et al., 2015).

To determine the first AIE we calculate the contribution of residential emissions to CDNC. We calculate CDNC using the parameterisation of cloud drop formation (Nenes and Seinfeld, 2003; Fountoukis and Nenes, 2005; Barahona et al., 2010) as described by Pringle et al. (2009). The maximum supersaturation $\left(\mathrm{SS}_{\max }\right)$ of an ascending cloud parcel depends on the competition between increasing water vapour saturation with decreasing pressure and temperature and the loss of water vapour through condensation onto activated particles. Monthly mean aerosol size distributions are converted to a supersaturation distribution where the number of activated particles can be determined for the $\mathrm{SS}_{\max }$. CDNC are calculated using a constant up-draught velocity of $0.15 \mathrm{~ms}^{-1}$ over sea and $0.3 \mathrm{~ms}^{-1}$ over land, which is consistent with observations for low-level stratus and stratocumulus clouds (Pringle et al., 2012). In reality, up-draught velocities vary, but the use of average velocities in previous GLOMAP studies has been shown to capture observed relationships between particle number and CDNC (Pringle et al., 2009), as well as reproducing realistic CDNC (Merikanto et al., 2010). The AIE is calculated using the methodology described previously (Spracklen et al., 2011a; Schmidt et al., 2012; Scott et al., 2014) where a control uniform cloud droplet effective radius $r_{\mathrm{e} 1}=10 \mu \mathrm{m}$ is assumed to maintain consistency with the ISCCP determination of liquid water path. For each perturbation experiment the effective radius $r_{\mathrm{e} 2}$ is calculated:

$r_{\mathrm{e} 2}=r_{\mathrm{e} 1} \times\left(\mathrm{CDNC}_{1} / \mathrm{CDNC}_{2}\right)^{\frac{1}{3}}$,

where $\mathrm{CDNC}_{1}$ represents a control simulation including residential emissions and $\mathrm{CDNC}_{2}$ represents a simulation where residential emissions have been removed. The AIE is calculated by comparing the net TOA radiative fluxes using the different $r_{\mathrm{e} 2}$ values derived for each perturbation experiment, to that of the control where $r_{\mathrm{e} 1}$ is fixed. We do not calculate the cloud lifetime (second indirect effect), semi-direct effects, or snow albedo changes. We also do not account for light absorbing brown carbon and the lensing effect of $\mathrm{BC}$ particles coated with a non-absorbing shell, and thus we are 
unable to estimate the full climate impact of residential combustion emissions.

\subsection{Model simulations}

Table 2 reports the model experiments used in this study. These simulations explore uncertainty in residential emission flux and emitted carbonaceous aerosol size distributions and the impact of particle formation. We test two different emission data sets (see Sect. 2.2 for details) allowing us to explore the role of seasonally varying emissions compared to annual mean emissions. We refer to the simulation using the ACCMIP emissions (annual mean emissions) with the standard model setup as the baseline simulation (res_base), while all other simulations explore key uncertainties relative to res_base or use the MACCity emission database of monthly varying anthropogenic emissions (res_monthly). To allow us to quantify the impact of residential emissions we conduct simulations where residential emissions (BC, $\mathrm{OC}$ and $\mathrm{SO}_{2}$ ) have been switched off (res_base_off and res_monthly_off). To account for uncertainties in the nucleation scheme, we conduct simulations where only BHN is able to contribute to new particle formation (res_BHN and res_BHN_off), while all other simulations include both BHN and BLN. For the majority of our simulations, we use $D$ and $\sigma$ recommended by Stier et al. (2005) $(D=150 \mathrm{~nm}$ $\sigma=1.59$ ). To account for the uncertainty in the size of emitted residential carbonaceous combustion aerosol and uncertainty of sub-grid ageing of the size distribution, we conduct simulations spanning the range of observed size distributions for primary $\mathrm{BC}$ and $\mathrm{OC}$ residential combustion particles, while keeping emission mass fixed. We use AeroCom (Dentener et al., 2006) recommended particle size settings (res_aero) $(D=80 \mathrm{~nm} \sigma=1.8)$ and, following a similar approach to Bauer et al. (2010), we use the range identified by Bond et al. (2006) for lower (res_small) $(D=20 \mathrm{~nm} \sigma=1.8)$ and upper (res_large) $(D=500 \mathrm{~nm} \sigma=1.8)$ estimates. To account for possible low biases in residential emission flux, we conduct simulations where residential primary carbonaceous combustion aerosol mass (BC and $\mathrm{OC}$ ) are doubled relative to the baseline simulation (res_ $\times 2$ ) and the simulation using monthly mean anthropogenic emissions (res_monthly_ $\times 2$ ). We also perform experiments where only residential $\mathrm{BC}$ and OC emissions are doubled separately relative to the baseline simulation (res_BC $\times 2$ and res_POM $\times 2$ ) to explore uncertainties in both emission mass flux and emission ratio. While the uncertainties in primary carbonaceous aerosol emissions are thought to be higher than for gas-phase $\mathrm{SO}_{2}$ (Klimont et al., 2009), we also conduct an experiment where we double residential $\mathrm{SO}_{2}$ emissions (res_SO2 2 2).

\section{Results}

\subsection{Model evaluation}

Figure 3 compares observed and simulated monthly mean $\mathrm{BC}, \mathrm{OC}$, and $\mathrm{PM}_{2.5}$ concentrations and normalised mean bias factor (NMBF) (Yu et al., 2006), where $M_{i}$ are the simulated concentrations by the model and $O_{i}$ are the observed concentrations at each measurement location, $i$,

$$
\begin{aligned}
& \mathrm{NMBF}=\frac{\sum\left(M_{i}-O_{i}\right)}{\sum O_{i}} \text { if } \bar{M} \geq \bar{O} \text { and } \\
& \mathrm{NMBF}=\frac{\sum\left(M_{i}-O_{i}\right)}{\sum M_{i}} \text { if } \bar{M}<\bar{O} .
\end{aligned}
$$

The baseline simulation underestimates observed $\mathrm{BC}$ $(\mathrm{NMBF}=-2.33), \quad \mathrm{OC} \quad(\mathrm{NMBF}=-5.02), \quad$ and $\quad \mathrm{PM}_{2.5}$ $(\mathrm{NMBF}=-1.33)$ concentrations. The greatest model underprediction is across East Asia (BC: $\mathrm{NMBF}=-2.61$, OC: $\mathrm{NMBF}=-6.56$, and $\left.\mathrm{PM}_{2.5}: \mathrm{NMBF}=-1.94\right)$. Over South Asia the model is relatively unbiased against OC $(\mathrm{NMBF}=0.41)$ but underestimates $\mathrm{BC}(\mathrm{NMBF}=-2.54)$. In contrast, over Eastern Europe the model is unbiased against $\mathrm{BC}(\mathrm{NMBF}=0.01)$ but underestimates $\mathrm{OC}$ $(\mathrm{NMBF}=-2.63)$. The simulation with monthly varying emissions compares slightly better with observations compared to the baseline simulation but still underestimates $\mathrm{BC}(\mathrm{NMBF}=-2.29), \mathrm{OC}(\mathrm{NMBF}=-4.92)$, and $\mathrm{PM}_{2.5}$ $(\mathrm{NMBF}=-1.34)$, suggesting that seasonality in emissions has little impact on reducing model bias. The low bias in our model, particularly for $\mathrm{BC}$ and $\mathrm{OC}$, is consistent with previous modelling studies using bottom-up emission inventories in South Asia (Ganguly et al., 2009; Menon et al., 2010; Nair et al., 2012; Moorthy et al., 2013; Pan et al., 2015) and East Asia (Park et al., 2005; Koch et al., 2009; Fu et al., 2012). The contribution of residential emissions is illustrated by the model simulation where these emissions are switched off, with substantially greater underestimation of $\mathrm{BC}(\mathrm{NMBF}=-5.12), \quad \mathrm{OC} \quad(\mathrm{NMBF}=-11.46)$, and $\mathrm{PM}_{2.5}(\mathrm{NMBF}=-1.60)$ concentrations (Fig. 3d). Doubling residential carbonaceous emissions improves model agreement with observations, but the model still underestimates $\mathrm{BC}(\mathrm{NMBF}=-1.33), \mathrm{OC}(\mathrm{NMBF}=-2.96)$, and $\mathrm{PM}_{2.5}$ $(\mathrm{NMBF}=-1.17)$ concentrations.

Figure 4 compares observed and simulated concentrations for South Asian locations. The baseline simulation underestimates carbonaceous aerosol concentrations at all locations, although there is better agreement at Godavari and Hanimaadhoo. BC measurements at these two sites were made through thermal-optical methods, whereas other locations in South Asia used optical methods (Table 1). Different measurement techniques result in different mass concentrations (Stone et al., 2007) and may contribute to modelobservation errors. The emission inventory that we use is based on carbonaceous measurements using thermal-optical 


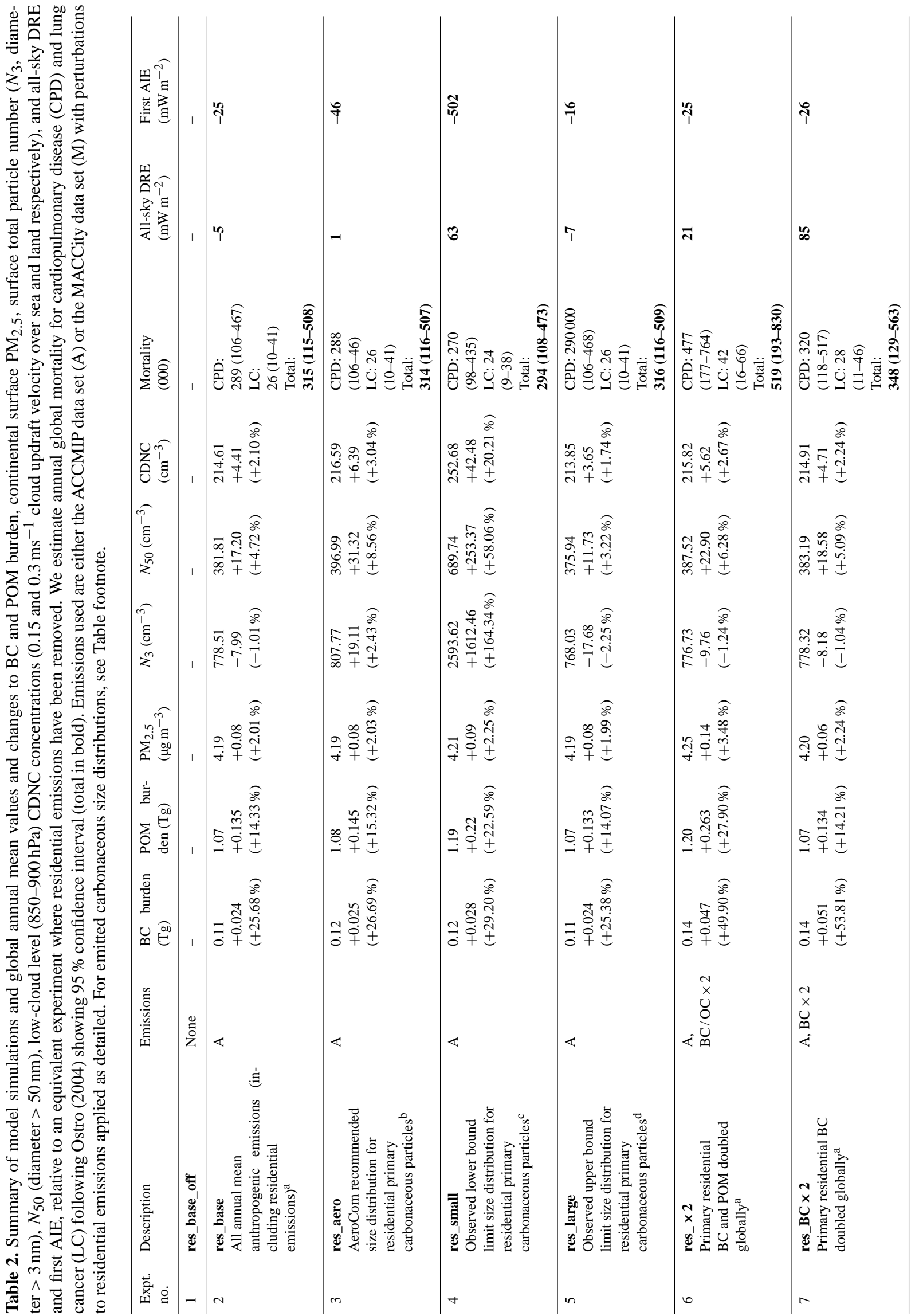




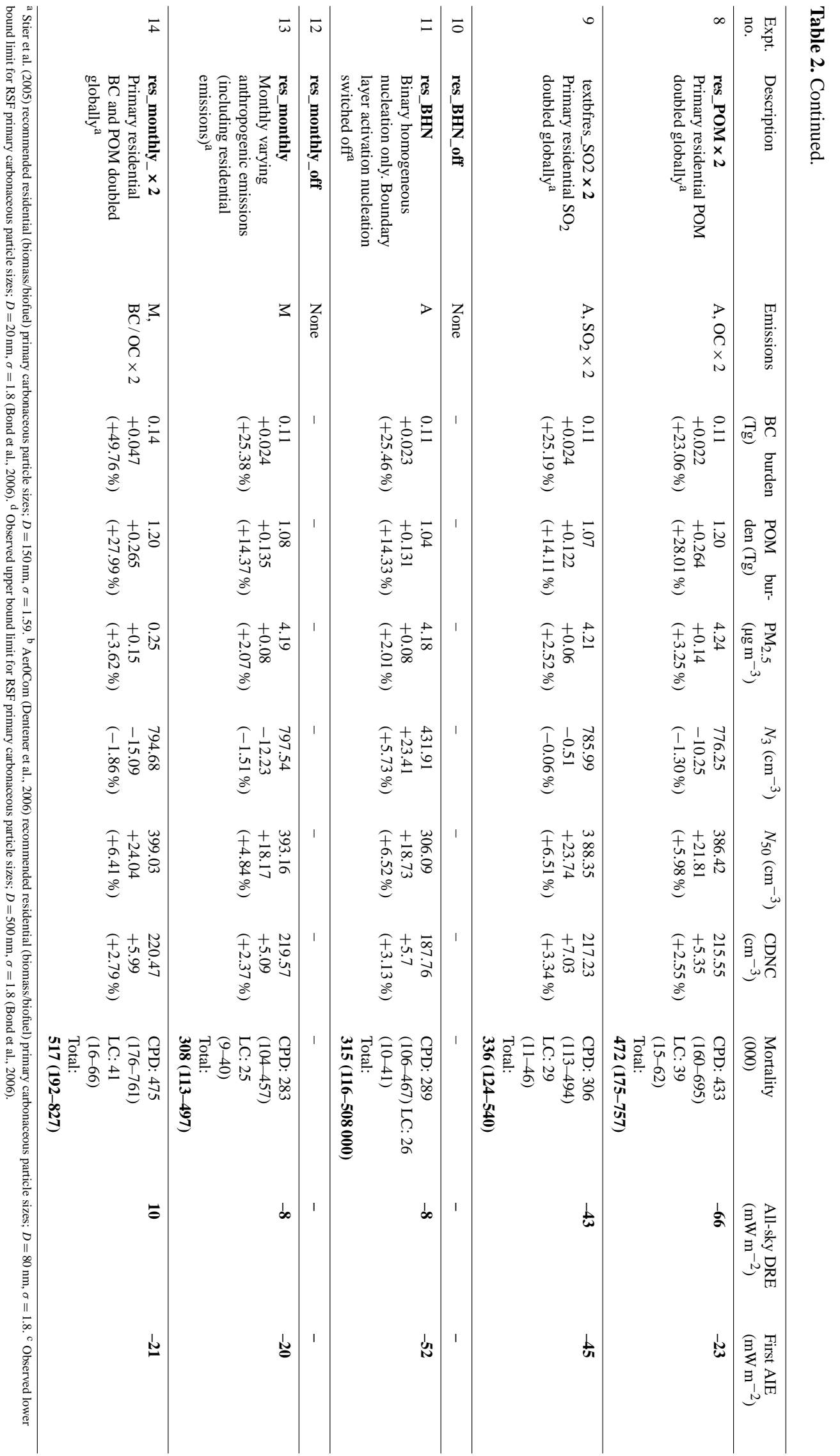


(a)

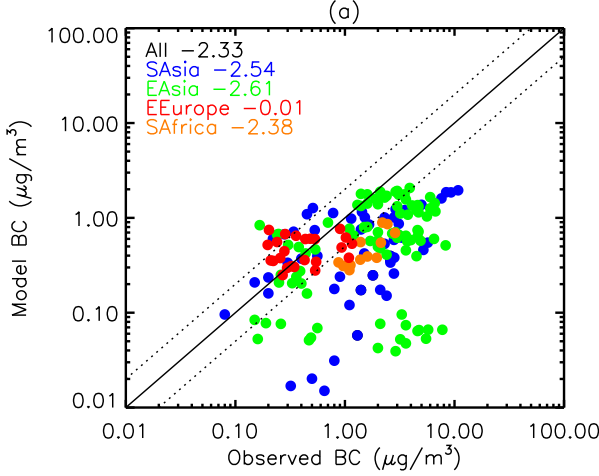

(c)

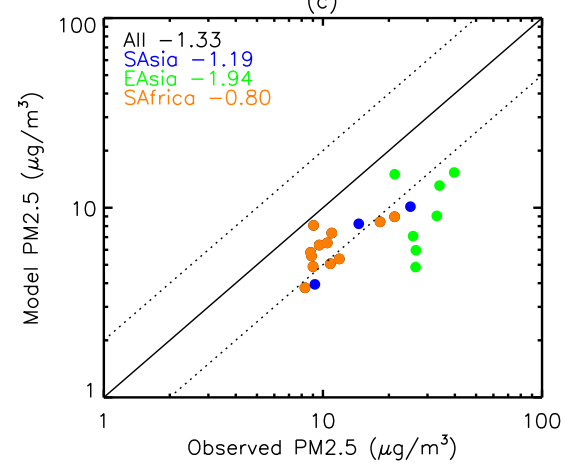

(b)

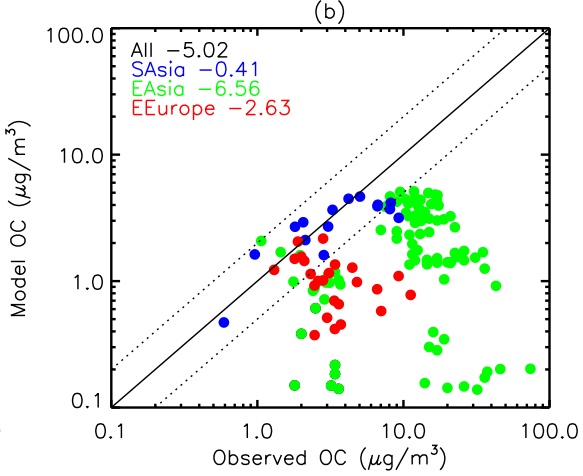

(d)

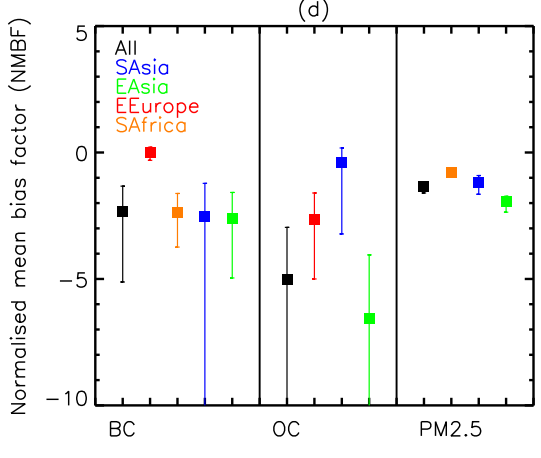

Figure 3. Observed and simulated monthly mean $\mathrm{BC}(\mathbf{a}), \mathrm{OC}(\mathbf{b})$, and $\mathrm{PM}_{2.5}$ (c) concentrations for the baseline simulation (res_base) using ACCMIP emissions at each measurement location depicted in Table 1 and normalised mean bias factor (NMBF) for each region defined in Table 1. (d) NMBF where square shows the baseline simulation, bottom error bar shows the range for removed residential emissions (res_base_off), and top error bar shows residential carbonaceous emissions doubled (res_× 2) for each region defined in Table 1. Colours represent observed, simulated, and NMBF for measurement location regions defined in Table 1: all measurement locations (All: black), South Asian locations (SAsia: blue), East Asian locations (EAsia: green), Eastern European locations (EEurope: red), and South African locations (SAfrica: orange).

methods (Bond et al., 2004), which might explain the better agreement at Godavari and Hanimaadhoo. Doubling residential carbonaceous emissions improves the comparison against observations but leads to slight overestimation at Godavari and Hanimaadhoo. Pan et al. (2015) found that seven different global aerosol models underpredicted observed BC by up to a factor 10, suggesting that anthropogenic emissions are underestimated in these regions.

Observed $\mathrm{BC}$ and $\mathrm{OC}$ concentrations show strong seasonal variability, with lower concentrations during the summer monsoon period (June-September). The baseline simulation generally captures this seasonality relatively well (correlation coefficient between observed and simulated monthly mean concentrations $r>0.5$ at most sites), with minimal improvement with monthly varying anthropogenic emissions. This suggests that meteorological conditions such as enhanced wet deposition during the summer monsoon period are the dominant drivers for the observed and simulated seasonal variability, consistent with other modelling studies for the same region (Adhikary et al., 2007; Moorthy et al., 2013). Model simulations where residential emissions have been switched off show that residential combustion contributes about two-thirds of simulated $\mathrm{BC}$ and $\mathrm{OC}$ at these locations. Figure $4 \mathrm{k}-1$ show a comparison of observed and simulated aerosol number concentrations at Hanimaadhoo. At this location, the baseline simulation simulates $N_{20}(\mathrm{NMBF}=0.14)$, $N_{50}(\mathrm{NMBF}=0.14)$ and $N_{100}(\mathrm{NMBF}=0.24)$ concentrations well. Simulated number concentrations are sensitive to emitted particle size. Emitting residential primary carbonaceous emissions at very small sizes (res_small) results in an overestimation of $N_{20}(\mathrm{NMBF}=1.84), N_{50}(\mathrm{NMBF}=1.28)$ and $N_{100}(\mathrm{NMBF}=1.05)$, suggesting that this assumption is unrealistic.

Figure 5 compares observed and simulated surface monthly mean $\mathrm{BC}$ and $\mathrm{OC}$ concentrations for East Asian locations. Observed surface $\mathrm{BC}$ and $\mathrm{OC}$ concentrations are generally enhanced during winter (December-February) compared to the summer (June-August). At all locations, the model underestimates BC (except for Gosan) and OC concentrations. The baseline simulation underpredicts both $\mathrm{BC}$ $(\mathrm{NMBF}<-2)$ and $\mathrm{OC}(\mathrm{NMBF}<-6)$ at Gaolan Shan and Longfengshan (as well as Akdala, Dunhuang, and Wusumu, which are not shown in Fig. 5), which is consistent with a previous model study at these locations (Fu et al., 2012). 

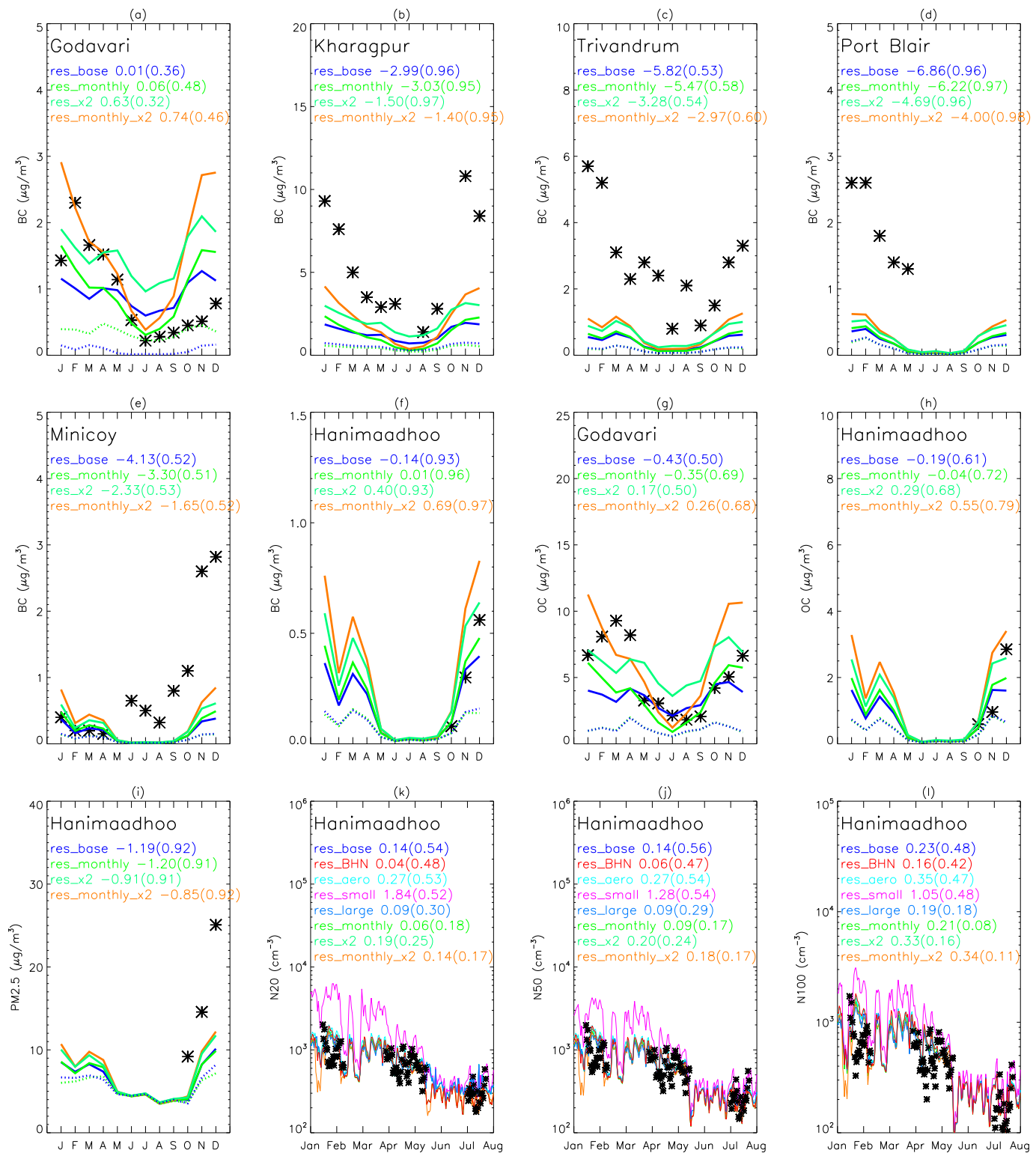

Figure 4. Observed (black stars) and simulated monthly mean $\mathrm{BC}(\mathbf{a}-\mathbf{f}), \mathrm{OC}(\mathbf{g}-\mathbf{h}), \mathrm{PM}_{2.5}(\mathbf{i})$, and daily mean $N_{20}(\mathbf{k}), N_{50}(\mathbf{j})$, and $N_{100}$ (l) at South Asian locations. Normalised mean bias factor (NMBF) and correlation coefficient $(r)$ are reported for each model simulation: $\operatorname{NMBF}(r)$. Experiments where residential emissions have been removed are represented by the blue (res_base_off) and green (res_monthly_off) dotted lines. Note that additional experiments (res_BHN, res_aero, res_small, and res_large) are included in (k)-(i) because these experiments have little impact on aerosol mass $(\mathbf{a}-\mathbf{j})$.

The substantial underestimation at some locations (e.g. Dunhuang, Gaolan Shan, and Wusumu) may be due to local particulate sources that are not resolved by coarse model resolution. If we exclude these locations, NMBF improves for $\mathrm{BC}(-2.61$ to -1.34$)$ and $\mathrm{OC}(-4.43$ to -3.29$)$ for the East Asian region. The model better simulates $\mathrm{BC}(\mathrm{NMBF}<-1)$ and $\mathrm{OC}(\mathrm{NMBF}<-2)$ at Taiyangshan and Jinsha, although the model is still biased low. The baseline simulation, without seasonally varying emissions, fails to capture the observed seasonal variability in East Asia, with negative correlations between observed and simulated aerosol concentrations at a number of locations. Fu et al. (2012) suggests that residential emissions (most likely heating sources) were the principle driver of simulated seasonal variability of EC (BC) at these locations. Implementing monthly varying anthropogenic emissions (including residential emissions) generally improves the simulated seasonal variability $(r>0.3$ at most sites) compared to using annual mean emissions. Doubling residential carbonaceous emissions also leads to improved NMBF at most locations. Residential emissions typi- 

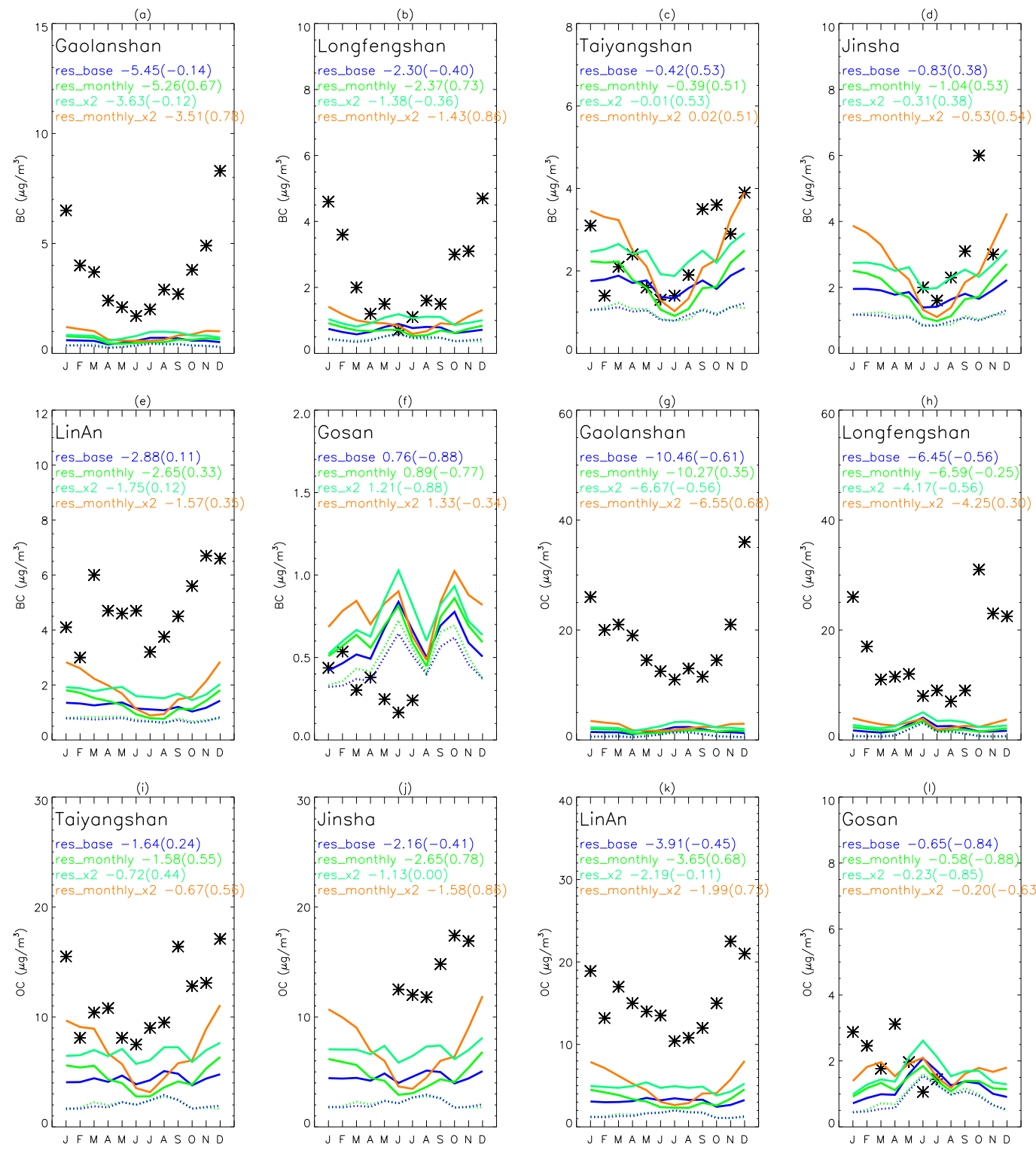

Figure 5. Observed (black stars) and simulated monthly mean BC (a-f) and OC (g-l) at East Asian locations. Normalised mean bias factor (NMBF) and correlation coefficient $(r)$ are reported for each model simulation: $\mathrm{NMBF}(r)$. Experiments where residential emissions have been removed are represented by the blue (res_base_off) and green (res_monthly_off) dotted lines.

cally account for 50-65\% of simulated BC and OC concentrations at these locations.

Figure 6 compares simulated and observed aerosol at South African and Eastern European locations. Marikana, Botsalano, and Welgegund are all located within the same region of South Africa and are influenced by both residential emissions and open biomass burning during the dry season, of which open biomass burning savannah fire seasonality peaks in July-September (Venter et al., 2012; Vakkari et al., 2013). Simulated aerosol number concentrations $\left(N_{20}\right.$ and $\left.N_{100}\right)$ are underestimated at Marikana, consistent with the underprediction in $\mathrm{BC}$ at the same lo- cation, while number concentrations are better simulated at Botsalano and Welgegund. The model underprediction at Marikana is likely due to the location being closer to emission sources, compared to Botsalano and Welgegund. For $N_{100}$ the model is generally good at simulating open biomass savannah burning seasonality (peaking in AugustSeptember), but increases in observed $N_{100}$ earlier in the season (May-August at Marikana and July at Welgegund) are not simulated. At both locations this early season maxima is likely due to residential emissions (Vakkari et al., 2013), which suggests that residential emissions are underrepresented in the model possibly due to resolution effects. 

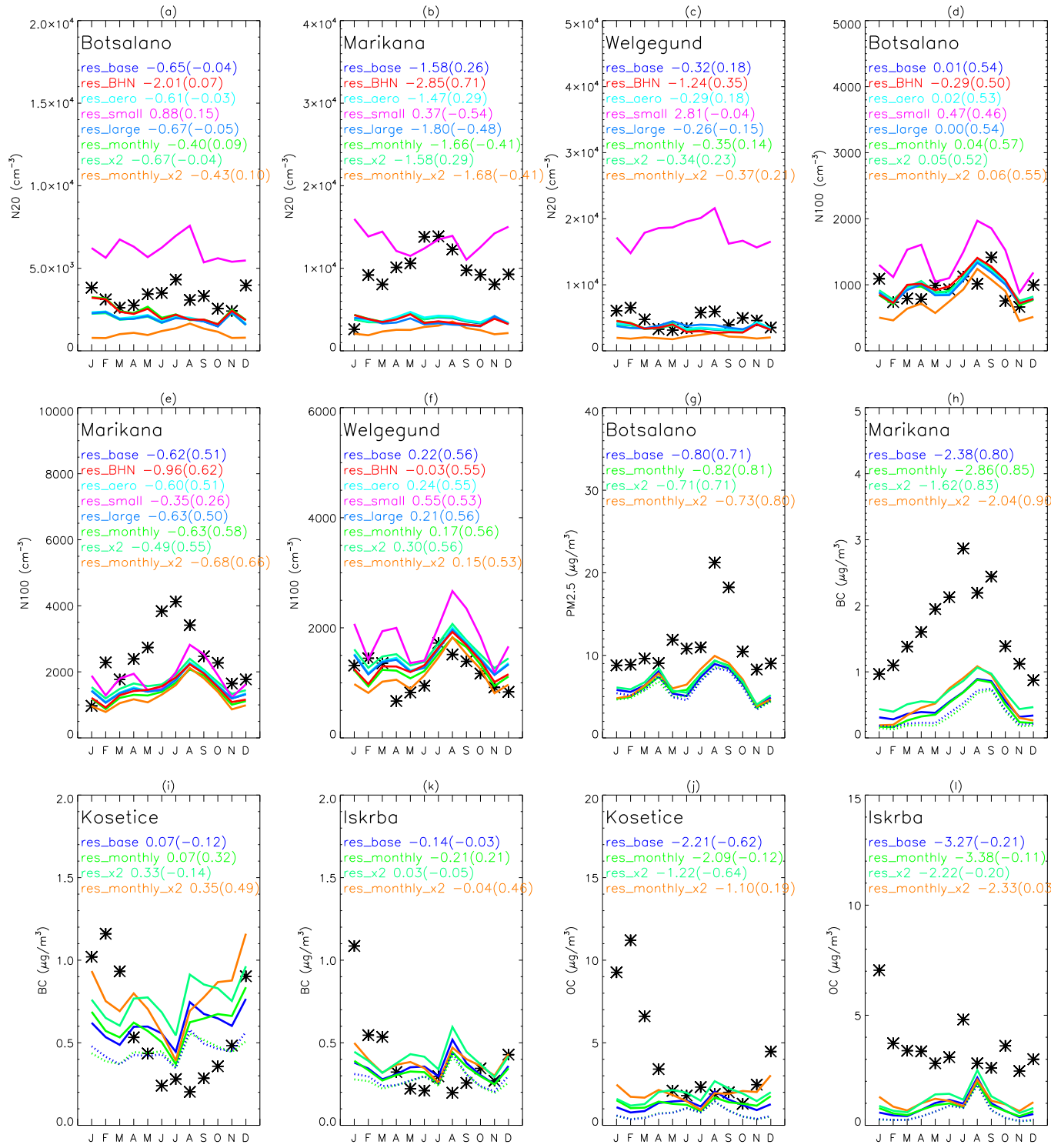

Figure 6. Observed (black stars) and simulated monthly mean $N_{20}(\mathbf{a}-\mathbf{c}), N_{100}(\mathbf{d}-\mathbf{f}), \mathrm{PM}_{2.5}(\mathbf{g}), \mathrm{BC}(\mathbf{h}-\mathbf{k})$, and OC (j-l) at South African and Eastern European locations. Normalised mean bias factor (NMBF) and correlation coefficient $(r)$ are reported for each model simulation: $\operatorname{NMBF}(r)$. Experiments where residential emissions have been removed are represented by the blue (res_base_off) and green (res_monthly_off) dotted lines. Note that additional experiments (res_BHN, res_aero, res_small, and res_large) are included in (a)-(f) because these experiments have little impact on aerosol mass (g-i).

Aerosol number concentrations at Botsalano $(\mathrm{NMBF}=0.47$ to 1.01$)$ and Welgegund $(\mathrm{NMBF}=0.55$ to 2.81$)$ are overestimated when primary carbonaceous particles are emitted at the smallest size (res_small), matching comparisons in South Asia and further suggesting that this assumption is unrealistic. The baseline simulation underestimates BC at Marikana $(\mathrm{NMFB}=-2.38)$ and $\mathrm{PM}_{2.5}$ concentrations at Botsalano $(\mathrm{NMBF}=-0.88)$, with a reduction in $\mathrm{BC}$ bias when residential carbonaceous emissions are doubled $(\mathrm{NMBF}=-1.62)$. At both these locations the model simulates a reasonable seasonality even without monthly varying residential emissions $(r>0.7)$, possibly due to strong seasonality in open biomass savannah burning emissions.

Similar to other locations, observed BC and OC concentrations in Eastern Europe (Fig. 6i-1) are enhanced during winter (December-February). The baseline simulation performs well at simulating $\mathrm{BC}$ at Košetice $(\mathrm{NMBF}=+0.07)$ and Iskrba $(\mathrm{NMBF}=-0.14)$ but underestimates OC at Košetice $(\mathrm{NMBF}=-2.21)$ and Iskrba $(\mathrm{NMBF}=-3.27)$. Model agreement does not improve much when monthly varying anthropogenic emissions are used. The model performs bet- 
(a)

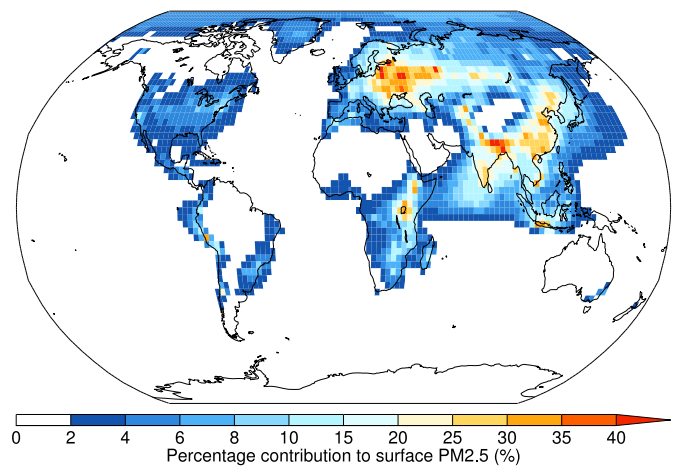

(c)

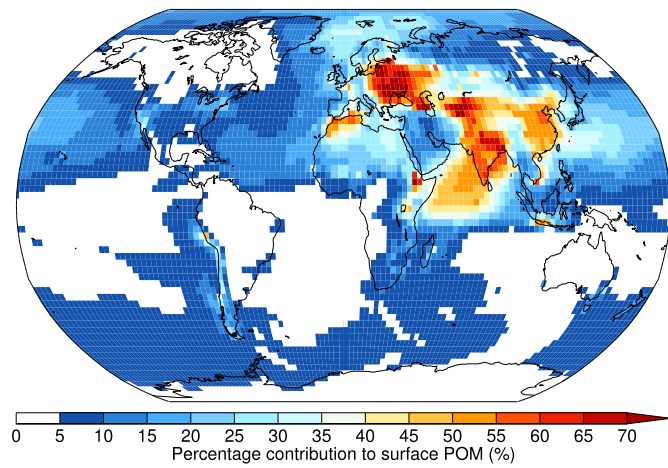

(b)

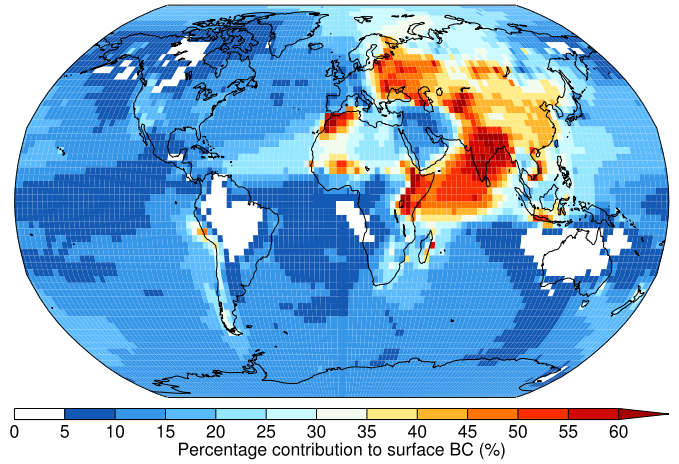

(d)

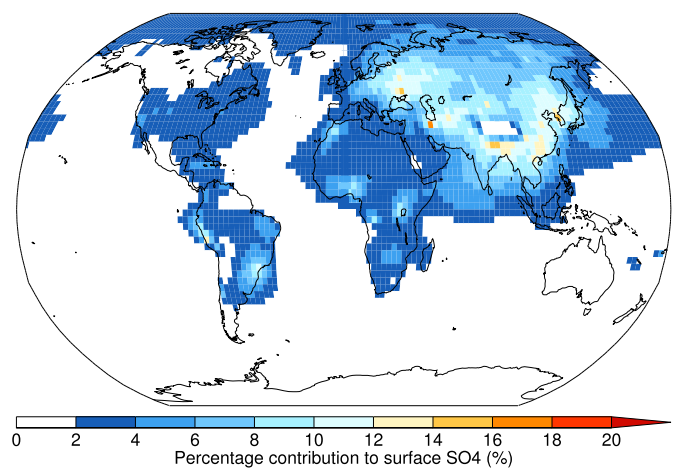

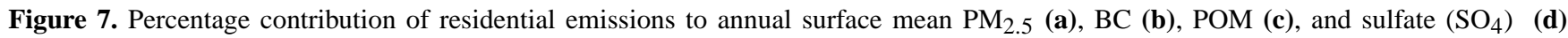
concentrations (in size fraction $\mathrm{PM}_{2.5}$ ) for the baseline simulation (res_base), relative to an equivalent simulation where residential emissions have been removed (res_base_off).

ter when residential carbonaceous emissions are doubled, but overestimates BC at Košetice.

In summary, we find the model typically underestimates observed $\mathrm{BC}$ and $\mathrm{OC}$ mass concentrations, which matches results from previous studies. Doubling residential emissions improves comparison against $\mathrm{BC}$ and $\mathrm{OC}$ observations, although the model is still typically biased low. To explore this further, we use ${ }^{14} \mathrm{C}$ analysis (Sect. 3.2) to evaluate the contribution of residential emissions to carbonaceous aerosol. In general, the model compares better against observations of particle number, except when carbonaceous particles are emitted at small sizes leading to large overestimates in particle number.

\subsection{Contribution of residential emissions to PM concentrations}

Figure 7 shows the fractional contribution of residential emissions to annual mean surface $\mathrm{PM}_{2.5}, \mathrm{BC}, \mathrm{POM}$, and sulfate concentrations for the baseline simulation. Greatest fractional contributions ( 15 to $>40 \%$ ) to surface $\mathrm{PM}_{2.5}$ are simulated over Eastern Europe (including parts of the Russian Federation), parts of East Africa, South Asia, and East Asia. Over these regions residential emissions contribute annual mean $\mathrm{PM}_{2.5}$ concentrations of up to $6 \mu \mathrm{g} \mathrm{m}^{-3}$, dominated by changes in POM concentrations of $2-5 \mu \mathrm{g} \mathrm{m}^{-3}$, with BC and sulfate contributing up to $1 \mu \mathrm{g} \mathrm{m}^{-3}$. Residential emissions contribute up to $60 \%$ of simulated $\mathrm{BC}$ and POM over parts of Eastern Europe, Russian Federation, Asia, southeastern Africa, and northwestern Africa. Contribution of residential emissions to surface sulfate concentrations are typically smaller, with contributions of $10-14 \%$ over parts of Asia, Eastern Europe, and the Russian Federation where residential coal emissions are more important (see Sect. 2.2). Over China, residential emissions account for $13 \%$ of simulated annual mean $\mathrm{PM}_{2.5}$, with larger contributions of $20-30 \%$ in the eastern China. Over India, residential emissions account for $22 \%$ of simulated annual mean $\mathrm{PM}_{2.5}$, with contributions $>40 \%$ over the Indo-Gangetic Plain. The contributions to $\mathrm{PM}_{2.5}$ are increased to $21 \%$ for China and $34 \%$ for India, when residential carbonaceous emissions are doubled. The contribution of residential emissions to annual mean surface $\mathrm{BC}(\mathrm{POM})$ concentrations is $\sim 40 \%(44 \%)$ for China and $\sim 60 \%$ (58\%) for India. When residential carbonaceous emissions are doubled, BC (POM) contributions are increased to $55 \%(60 \%)$ for China and $75 \%$ (73\%) for India. 
The absolute contribution of residential emissions to PM concentrations are greatest in the $\mathrm{NH}$ between 0 and $60^{\circ} \mathrm{N}$ below $500 \mathrm{hPa}$ (not shown). The fractional contributions within this region are up to $16-24 \%$ for both $\mathrm{BC}$ and POM and 1-4\% for sulfate. Residential emissions contribute $\sim 20 \%$ of BC and $\sim 12-16 \%$ of POM aloft (above $500 \mathrm{hPa}$ ) but cause small reductions in sulfate $(-1$ to $-4 \%)$ due to the suppression of nucleation and growth (see Sect. 3.4 for more details).

Table 2 reports the impact of residential emissions on simulated global annual mean BC and POM burden and continental surface $\mathrm{PM}_{2.5}$ concentrations. In the baseline simulation, the global BC burden is $0.11 \mathrm{Tg}$ with a global mean atmospheric BC lifetime of 4.95 days. This lifetime matches the 4.4 to 5.1 days reported by X. Wang et al. (2014), suggesting that our underestimation of observed $\mathrm{BC}$ is not due to fast deposition and short atmospheric lifetime, at least in comparison to other models. In the baseline simulation, residential emissions result in a global BC burden of $0.024 \mathrm{Tg}$, contributing $22 \%$ of the global BC burden. Residential emissions contribute $12 \%$ of global POM burden. When residential carbonaceous emissions are doubled, residential emissions contribute $33 \%$ of the BC burden and $23 \%$ of the POM burden. Changing from annual mean to monthly varying emissions results in little change to the global $\mathrm{BC}$ or POM burden. Emitting carbonaceous particles at very small sizes (res_small) results in a greater fractional contribution to global atmospheric BC $(\sim 23 \%)$ and POM $(\sim 18 \%)$ and longer BC lifetime (5.4 days) compared to the baseline simulation. Because the removal of carbonaceous particles in the model is size dependant (particularly for wet deposition), small particles below a critical size can escape removal, leading to enhanced lofting to the free troposphere (FT) where deposition rates are slow. In the res_small simulation, fractional changes in BC burden can be as large as 60-100\% in the FT, compared to $25-40 \%$ in the baseline simulation. Continental surface $\mathrm{PM}_{2.5}$ concentrations are increased by $\sim 2 \%$ in the baseline simulation, which is increased to $\sim 3.6 \%$ when carbonaceous residential emissions are doubled.

We further evaluate the simulated contribution of residential emissions to $\mathrm{BC}$ concentrations using ${ }^{14} \mathrm{C}$ source apportionment studies on the island of Hanimaadhoo (Gustafsson et al., 2009; Sheesley et al., 2012; Bosch et al., 2014), which is influenced by pollution transported from the Indian subcontinent. The model simulates well both $\mathrm{BC}$ and $\mathrm{OC}$ concentrations observed at this location (Sect. 3.1). Figure 8 compares simulated and observed biomass contributions to $\mathrm{BC}$ at Hanimaadhoo. The observed contribution depends on not only the time of year the measurements were taken but also the measurement technique used to derive BC (EC). For example, during the same measurement period Gustafsson et al. (2009) found that $46 \pm 8 \%$ of $\mathrm{EC}$ and $68 \pm 6 \%$ of $\mathrm{BC}$ originated from non-fossil biomass (January-March). Bosch et al. (2014) estimate that $59 \pm 8 \%$ of EC is from non-fossil

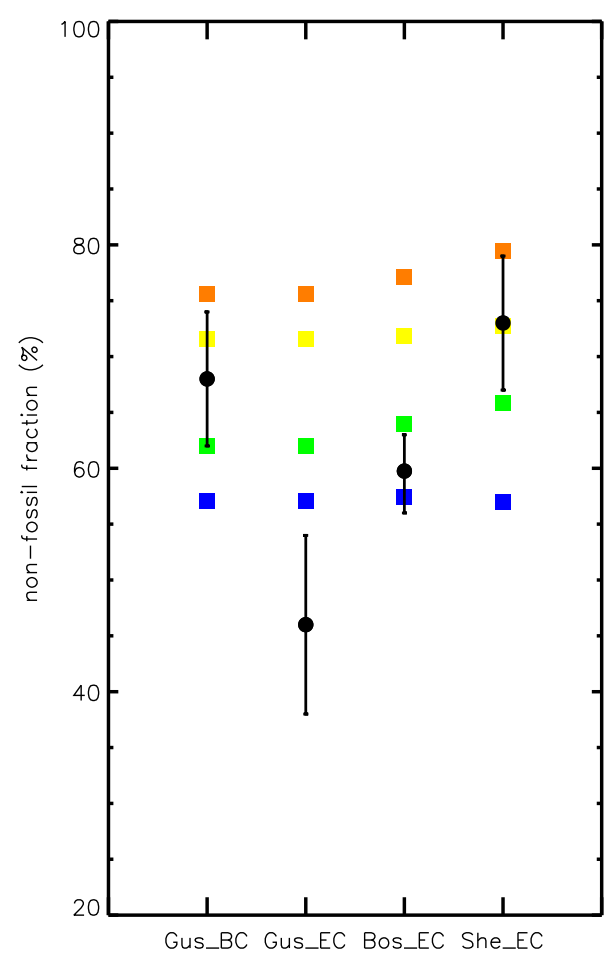

Figure 8. Comparison of simulated (squares) and observed (circles, error bars show uncertainty range) contributions of nonfossil (residential biofuel and open biomass burning) sources to BC concentrations in Hanimaadhoo, Indian Ocean. Observations are from Gustafsson et al. (2009) ("Gus EC" (thermo-optical) and "Gus BC" (optical) for January-March), Bosch et al. (2014) ("Bos EC" (thermo-optical) for February-March), and Sheesley et al. (2012) ("She EC" (thermo-optical) for November-February). Model simulations are represented by squares: standard emissions (blue: res_base; green: res_monthly) and where residential carbonaceous emissions have been doubled (yellow: res_ $\times 2$; orange: res_monthly_ $\times 2$ ). Simulated fractional contributions are averaged over the time of year that the observations were made.

biomass (February-March). Sheesley et al. (2012) estimated that $73 \pm 6 \%$ of EC originated from non-fossil biomass during the dry season (November-February). The observed contribution of non-fossil BC (EC) therefore spans a range of 46-73\%. Residential biofuel/biomass combustion dominates residential emissions in South Asia (Venkataraman et al., 2005). To estimate non-fossil values from the model, we assume that $90 \%$ of residential BC transported to Hanimaadhoo originates from residential biofuel sources (consistent with $\geq 90 \%$ estimates from the GAINS model), while the remaining non-fossil $\mathrm{BC}$ originates from open biomass burning (including agricultural waste and open waste/rubbish burning). We find a small contribution $(<10 \%$ for all simulations) of open biomass burning to simulated $\mathrm{BC}$ at Hanimaadhoo, confirming that the non-fossil contribution at this location is likely dominated by residential biomass/biofuel sources, which is supported by the observed consistent con- 


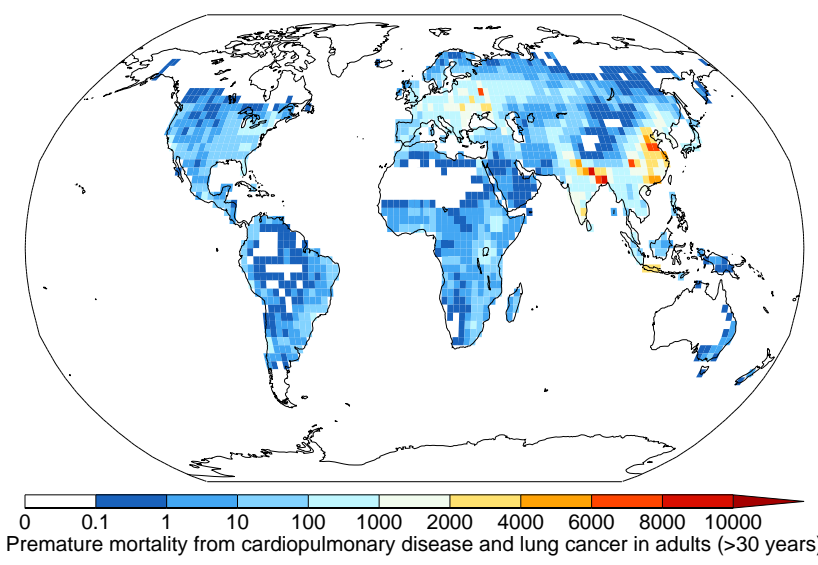

Figure 9. Simulated annual premature mortality (cardiopulmonary diseases and lung cancer) due to ambient exposure to ambient $\mathrm{PM}_{2.5}$ from residential emissions (res_base - res_off).

tribution from a non-fossil source (Sheesley et al., 2012). The simulated contribution of non-fossil sources to total BC at this location is $\sim 57-79 \%$, depending on the time of year and model simulation. The baseline simulation has a $57 \%$ contribution of non-fossil sources to simulated BC concentrations, with little variation between different times of year due to the annual mean emissions applied in this simulation. Model simulations with monthly varying emissions have a greater contribution of non-fossil sources to $\mathrm{BC}$ at this location, as well as greater variability between seasons with a contribution of $62-65 \%$. Doubling residential emissions increases the contribution of non-fossil sources to $\sim 72 \%$ for annual mean emissions and $\sim 76-79 \%$ for monthly varying emissions. The spread in observed EC contributions makes it difficult to constrain the contribution of residential emissions, with baseline and doubling of residential $\mathrm{BC}$ emissions bracketing the observed range. We do not analyse the nonfossil fraction of OC since OC arises from a larger range of sources including primary emissions and secondary organic aerosol (SOA). Nevertheless, non-fossil water-soluble organic carbon at Hanimaadhoo is dominated $(\sim 80 \%)$ by biomass and biogenic sources (Kirillova et al., 2013) but the relative enrichment in the stable $\left(\delta^{13} \mathrm{C}\right)$ carbon isotope points largely to aged primary biomass emissions sources (Bosch et al., 2014). We estimate the simulated biomass contribution to OC at Hanimaadhoo to be $\sim 50-70 \%$ for baseline simulations (res_base and res_monthly) and $\sim 70-80 \%$ for simulations where residential carbonaceous emissions have been doubled.

\subsection{Health impacts of residential emissions}

Figure 9 shows the simulated annual excess premature mortality due to exposure to ambient $\mathrm{PM}_{2.5}$ from residential emissions in the year 2000 for the baseline simulation. Greatest mortality is simulated over regions with substantial res-

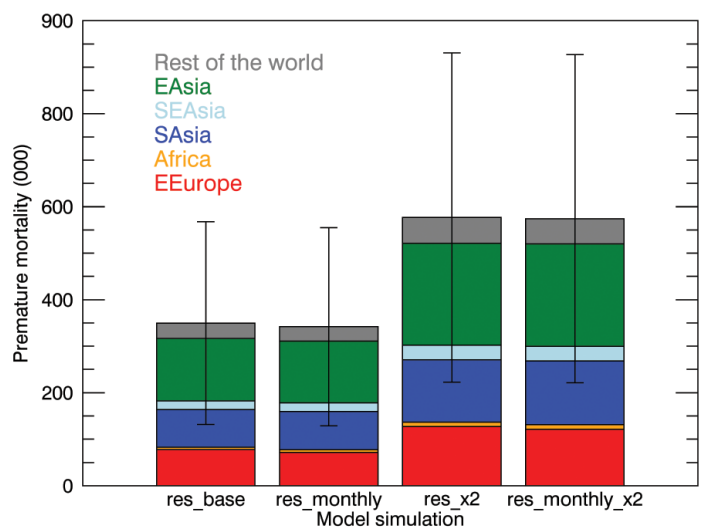

Figure 10. Simulated global annual premature mortality (cardiopulmonary diseases and lung cancer for persons over the age of 30 years) due to exposure to ambient $\mathrm{PM}_{2.5}$ from residential emissions. Results are shown for standard emissions (res_base and res_monthly) and where residential emissions have been doubled (res_x 2 and res_monthly_ $\times 2$ ). Mortality is shown for Eastern Europe and the Russian Federation (EEurope), Africa (Africa), South Asia (SAsia), Southeast Asia (SEAsia), East Asia (EAsia), and the rest of the world (as defined by the coloured regions in Fig. 2).

idential emissions and high population densities, notably parts of Eastern Europe, the Russian Federation, South Asia, and East Asia. Table 2 reports total global values for annual mortality due to residential emissions. For the baseline simulation, we estimate a total global annual mortality of 315000 (132000-508 000, 5th to 95th percentile uncertainty range). The simulation with monthly varying emissions (res_monthly) results in total global annual mortality of 308000 (113300-497000), only a $2 \%$ difference from the baseline estimate. Uncertainty in the magnitude of residential emissions causes substantial uncertainty in the simulated impact on human health. When residential carbonaceous emissions are doubled, annual premature mortality increases by $65 \%$ to 519000 (193000-830000) with annual mean emissions and by $68 \%$ to 517000 (192000827000 ) with monthly varying emissions. Therefore, uncertainty in the emission budget and uncertainty in the health impacts of PM (as specified by $95 \%$ confidence intervals in the cause-specific coefficients) result in similar uncertainties in estimated global mortality. The CRF function treats all aerosol components as equally harmful, so simulations where residential emissions of POM, BC, and $\mathrm{SO}_{2}$ are increased individually show that health effects are most sensitive to uncertainty in POM emissions because this component dominates the total emission mass. Doubling POM emissions (res_POM $\times 2$ ) increases estimated premature mortality by $50 \%$, whereas doubling $\mathrm{BC}$ emissions $\left(\right.$ res_BC $\times 2$ ) results in an $11 \%$ increase and doubling $\mathrm{SO}_{2}$ emissions (res_SO2 $\times 2$ ) leads to a $6.5 \%$ increase.

Figure 10 shows simulated annual total mortality by region. For the baseline simulation, we estimate that resi- 
(a)

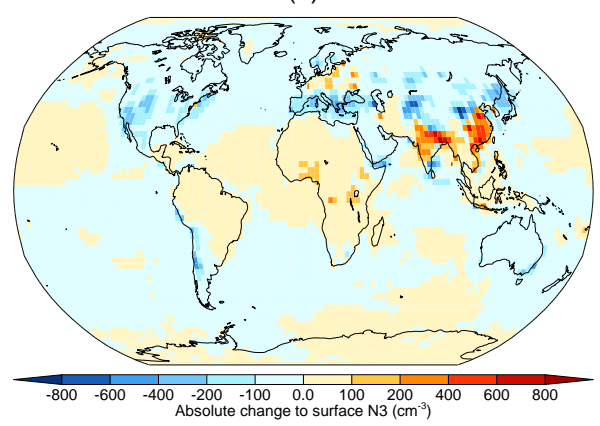

(c)

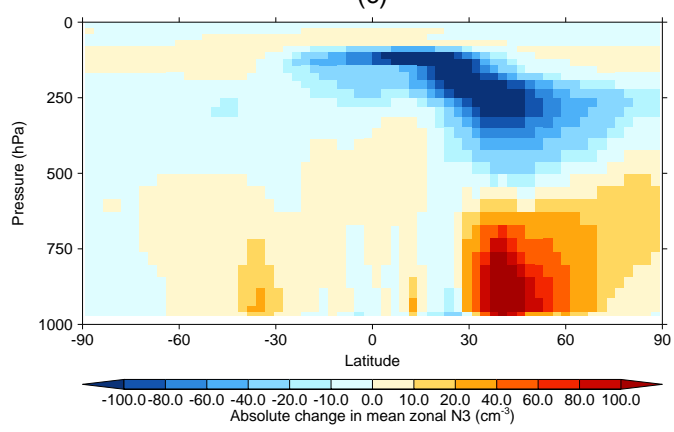

(b)

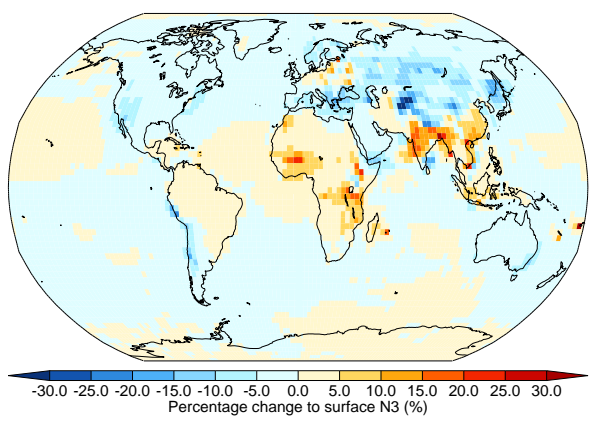

(d)

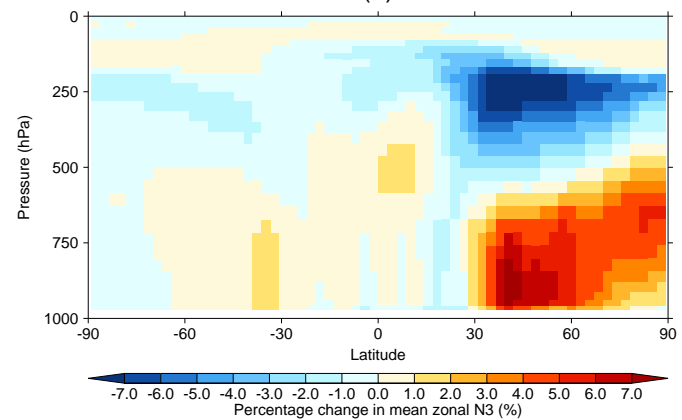

Figure 11. Simulated absolute and percentage change in annual mean surface (a-b) and zonal (c-d) number concentration $\left(N_{3}\right.$; greater than $3 \mathrm{~nm}$ dry diameter) due to residential emissions (res_base), relative to an equivalent simulation where residential emissions have been removed (res_base_off).

dential emissions cause the greatest mortality in East Asia with 121075 (44596-195443, 95\% confidence intervals) annual deaths $-38 \%$ of global mortalities due to residential emissions. We also calculate substantial health effects in other regions, with 72890 (26891-117360) annual deaths in South Asia (28\% of global mortalities) and 69757 (25 714112447 ) in Eastern Europe and Russia (22\% of global mortalities). Elsewhere we estimate lower mortality with 16723 (6152-27 018) annual deaths in Southeast Asia (5\%) and 4791 (1751-7784) in sub-Saharan Africa (2\%). Annual premature mortality in sub-Saharan Africa is less than in Asia due to a smaller contribution of residential emissions to $\mathrm{PM}_{2.5}$ concentrations (Fig. 7), combined with typically lower population densities, lower baseline mortality rates for lung cancer and cardiopulmonary disease, and a smaller fraction of the population over 30 years of age.

To our knowledge, this is the first study of the global excess mortality due to ambient $\mathrm{PM}_{2.5}$ from both residential cooking and heating emissions. A recent study by Chafe et al. (2014) concluded that ambient $\mathrm{PM}_{2.5}$ from RSF cooking emissions resulted in 420000 annual excess deaths in 2005 and 370000 annual excess deaths in 2010. Chafe et al. (2014) also simulated lower mortality in sub-Saharan Africa (10 800 deaths in 2005) compared to Asia, consistent with our findings. The regions where we estimate the largest health impacts due to residential emissions are dominated by
RSF emissions. In East Asia, residential emissions are dominated by both residential coal and biofuel sources whereas in South Asia emissions are dominated by biofuel sources (Bond et al., 2013).

\subsection{Impact of residential emissions on total particle number and $N_{50}$ concentrations}

Figure 11 shows the change in annual mean surface and zonal mean particle number concentration $\left(N_{3}\right.$; particles greater than $3 \mathrm{~nm}$ dry diameter) due to residential emissions for the baseline simulation. Residential emissions increase $N_{3}$ concentrations over source regions by up to $800 \mathrm{~cm}^{-3}$ due to primary emitted particles. Downwind of source regions, $\mathrm{N}_{3}$ concentrations are reduced by up to $\sim 400 \mathrm{~cm}^{-3}$. This reduction is caused by primary particles acting as a coagulation sink for nucleated particles and a condensation sink for nucleating and condensing vapours, suppressing new particle formation (Spracklen et al., 2006), which is broadly consistent with the findings of Kodros et al. (2015) for particle number concentrations due to the effect of biofuel emissions. Residential emissions decrease $N_{3}$ concentrations in the FT $\left(>500 \mathrm{hPa}\right.$ ) by up to $100 \mathrm{~cm}^{-3}(7 \%)$ due to suppression of nucleation and growth from reduced availability of $\mathrm{H}_{2} \mathrm{SO}_{4}$ vapour due to increased condensation on primary particles. 
(a)

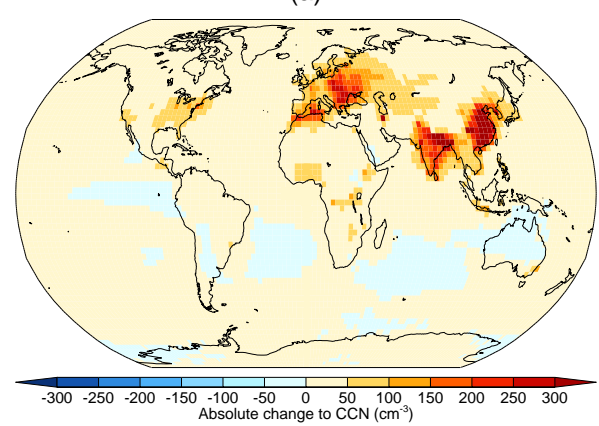

(c)

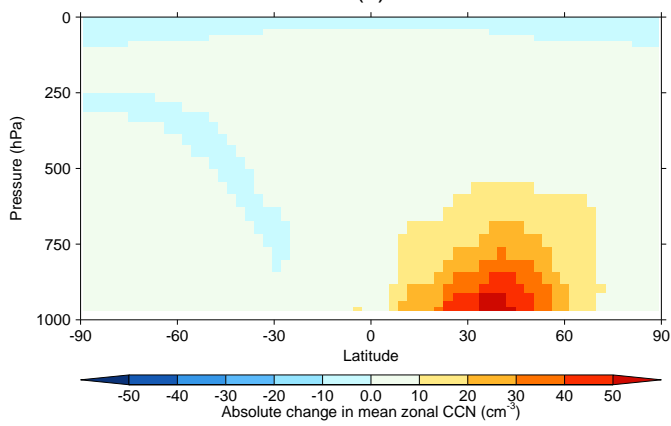

(b)

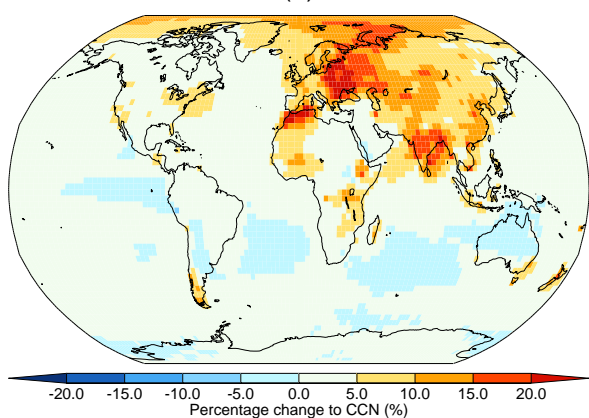

(d)

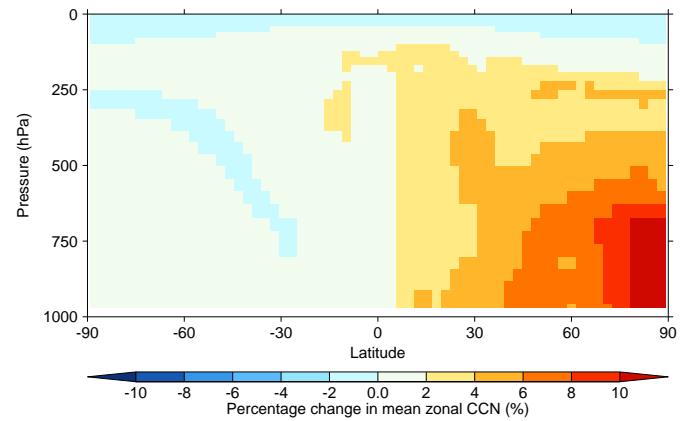

Figure 12. Simulated absolute and percentage change in annual mean surface (a-b) and zonal (c-d) soluble $N_{50}$ concentrations due to residential emissions (res_base), relative to an equivalent simulation where residential emissions have been removed (res_base_off).

In the baseline simulation, residential emissions reduce annual global mean $N_{3}$ concentrations by $1.0 \%$ (Table 2). When activation BLN is switched off (res_BHN), this suppression is no longer important, and residential emissions increase annual global mean $N_{3}$ concentrations by $5.7 \%$. The impact of residential emissions on global particle number depends on the assumed particle size of primary carbonaceous emissions. When residential carbonaceous emissions are emitted at smaller sizes (res_aero and res_small), global mean $N_{3}$ concentrations are increased by 2.4 and $164 \%$ respectively. This is because a greater number of particles are being emitted per emission mass compared to the baseline simulation.

Figure 12 shows the impact of residential emissions on surface and zonal mean soluble $N_{50}$ number concentrations for the baseline simulation. Residential emissions increase $N_{50}$ concentrations over source regions of East Asia, South Asia, and Eastern Europe by up to $300-500 \mathrm{~cm}^{-3}$. Simulated $N_{50}$ concentrations are increased by up to $20 \%$ in the Arctic, Eastern Europe, Russian Federation, North Africa, and South Asia. Despite high absolute changes, fractional changes in $N_{50}$ concentration over East Asia (e.g. China) are smaller $(<15 \%)$ because of higher baseline $N_{50}$ in this region from other sector emissions (e.g. from industry). $N_{50}$ concentrations increase globally due to residential emissions, but small reductions $(<5 \%)$ are simulated in the remote Southern Ocean because of the reduction in the amount of
$\mathrm{H}_{2} \mathrm{SO}_{4}$ and condensable vapour available for nucleation and growth in FT, which results in reduced entrainment of nucleated particles into the boundary layer. Absolute and fractional changes in zonal mean $N_{50}$ are greatest between 0 and $60^{\circ} \mathrm{N}$ and below $500 \mathrm{hPa}$.

Table 2 reports the global annual mean change in $N_{50}$ concentrations between different simulations. In the baseline simulation, residential emissions increase global mean surface $N_{50}$ by $\sim 5 \%$. When primary residential carbonaceous particles are emitted at smaller sizes, residential emissions cause a greater increase in $N_{50}$ concentrations, with annual global mean $N_{50}$ concentrations increasing by $\sim 20 \%$ in the simulation with smallest particle size (res_small). Emitting particles at larger sizes results in a smaller increase in global mean $N_{50}(3.1 \%)$ because large particles are more efficiently scavenged. The sensitivity of global mean $N_{50}$ concentrations to assumptions about emitted particle size is consistent with previous studies (Adams and Seinfeld, 2003; Spracklen et al., 2005b, 2011a). When residential carbonaceous aerosol emissions are doubled, residential emissions increase global annual mean $N_{50}$ by $\sim 6.3 \%$ (res_× 2 ). Simulations where individual carbonaceous components are doubled separately $\left(\right.$ res_BC $\times 2$ and $($ res_POM $\times 2)$ show that $N_{50}$ is mainly sensitive to change in $\mathrm{OC}$ emissions which dominate the carbonaceous aerosol mass. When residential $\mathrm{SO}_{2}$ emissions are doubled, residential emissions increase global annual mean $N_{50}$ by $6.5 \%$. When activation BLN is assumed not to oc- 
(a)

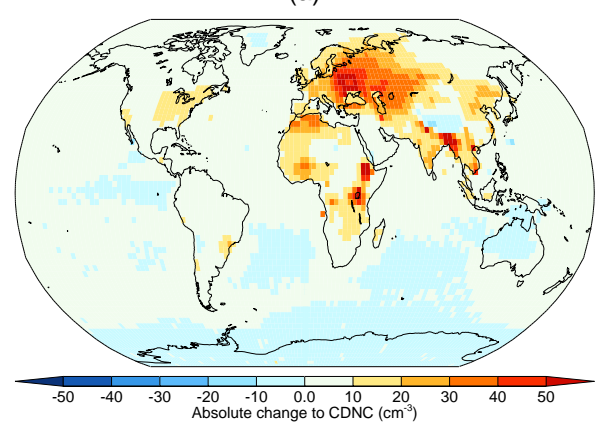

(c)

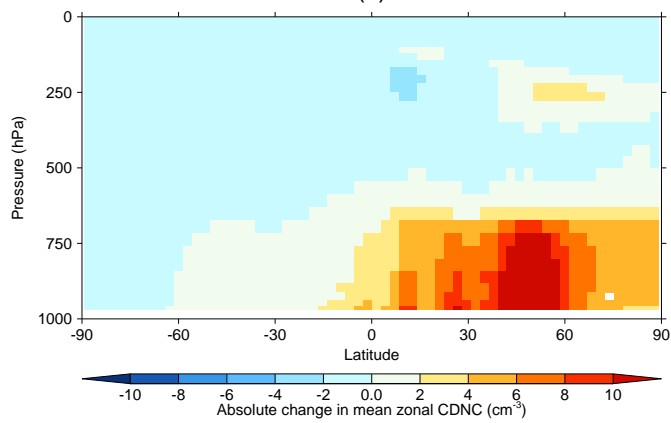

(b)

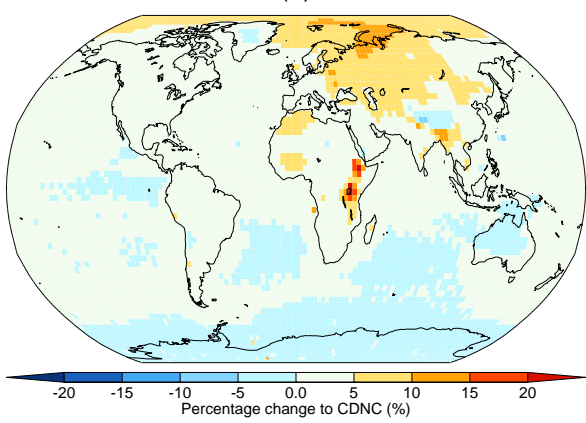

(d)

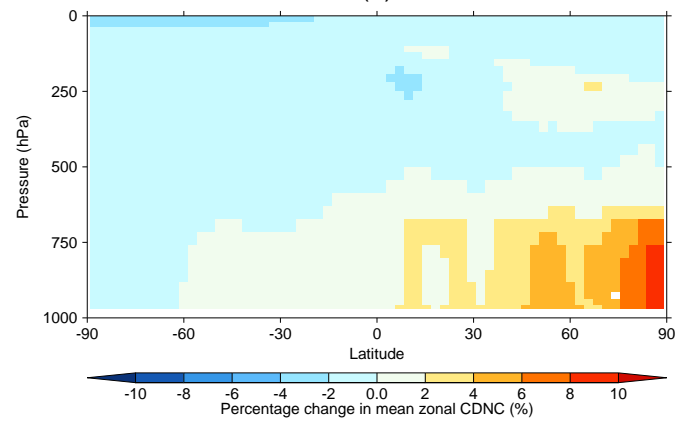

Figure 13. Simulated absolute and percentage change in annual mean at low cloud height (850-900 hPa) (a-b) and zonal (c-d) CDNC due to residential emissions (res_base), relative to an equivalent simulation where residential emissions have been removed (res_base_off).

cur, residential emissions increase global annual mean $N_{50}$ by $6.5 \%$ relative to the simulation with no residential emissions. This greater sensitivity is because the baseline $N_{50}$ concentrations without BLN are lower $\left(287.4 \mathrm{~cm}^{-3}\right)$ than the baseline simulation $\left(364.6 \mathrm{~cm}^{-3}\right)$.

\subsection{Impact of residential emissions on cloud droplet number concentrations}

Figure 13 shows the impact of residential emissions on annual mean low-cloud level (850-900 hPa) and zonal mean CDNC for the baseline simulation. Residential emissions increase low-cloud level CDNCs by $20-100 \mathrm{~cm}^{-3}$ over source regions. Smaller absolute and percentage changes in CDNC are simulated over regions with greater baseline CDNCs due to CDNC saturation effects. In contrast, CDNCs increases of $20 \%$ are simulated over regions with low simulated background CDNCs, including parts of East Africa. Simulated absolute increases in zonal mean CDNC are greatest between 0 and $60^{\circ} \mathrm{N}$ below $500 \mathrm{hPa}$, whereas greatest fractional changes occur in the Arctic (6-8\%) due to low background concentrations. Small reductions in CDNC are simulated in the FT $(\sim-2 \%)$ and in the remote Southern Ocean $(1-2 \%)$ at cloud level. This is caused by suppressed nucleation in the FT.

In the baseline simulation, residential emissions increase global annual low-cloud level CDNC by $2.1 \%$ (Table 2).
Uncertainty in the emitted particle size of primary carbonaceous emissions causes most of the uncertainty in simulated CDNC. When residential carbonaceous particles are emitted at smaller sizes (res_small) emissions increase global annual mean CDNC by $20 \%$. Emitting particles at smaller sizes resulted in greater $N_{50}$ concentrations, meaning more CCNsized particles are available to activate. While larger particle sizes can active cloud drops more easily compared to smaller particles, large particles will deplete available water vapour more quickly, which will lower $\mathrm{SS}_{\max }$, leading to a suppression of small particles being activated. When activation BLN is switched off (res_BHN), residential emissions cause a greater increase in CDNC (3\%) compared to the baseline simulation, due to lower background CDNCs. Annual mean CDNC are increased by $+2.7 \%$ when primary carbonaceous emissions are doubled (res_ $\times 2$ ), but greater increases $(+3.3 \%)$ are simulated when residential $\mathrm{SO}_{2}$ is doubled separately (res_SO2 $\times 2$ ). This suggests that residential $\mathrm{SO}_{2}$ is having a greater effect on $\mathrm{CDNC}$ compared to carbonaceous emissions because the small size distribution of secondary sulfate is more efficient in the activation of cloud drops.

\subsection{Radiative effects of residential emissions}

Figure 14 shows annual mean all-sky TOA DRE and first AIE due to residential emissions for the baseline simulation. 

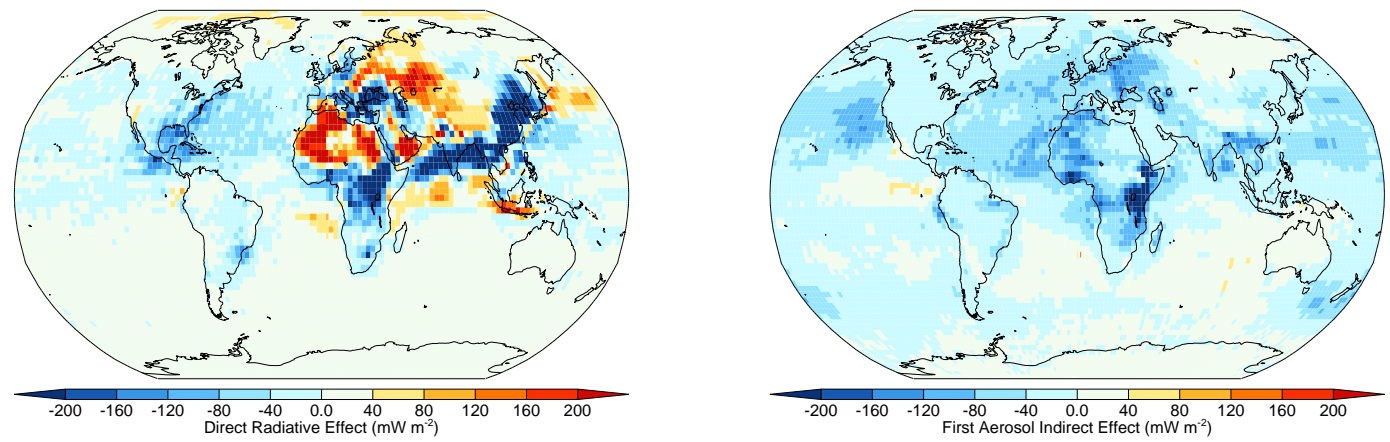

Figure 14. Annual mean all-sky direct radiative effect (DRE) (left panel) and first aerosol indirect effect (AIE) (right panel) due to residential emissions (res_base), relative to an equivalent simulation where residential emissions have been removed (res_base_off).

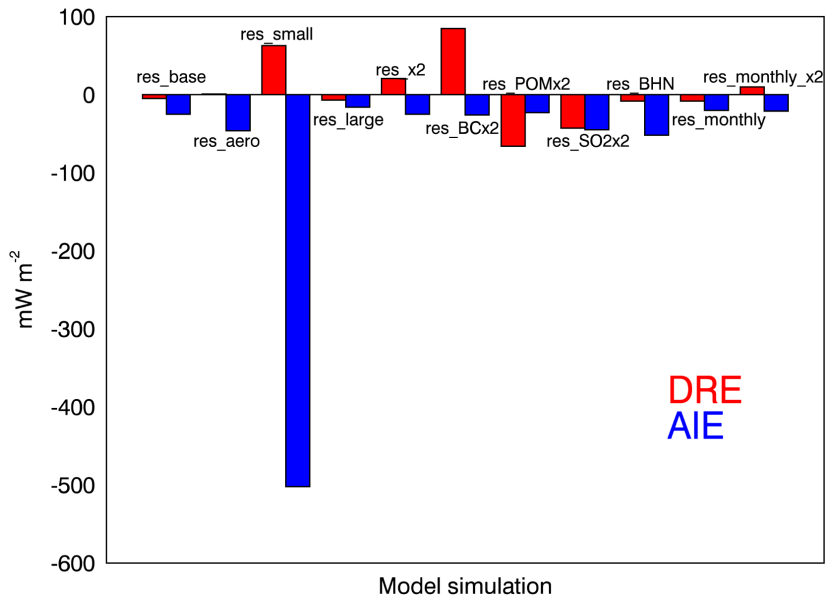

Figure 15. Global annual mean all-sky direct radiative effect (DRE) (red) and first aerosol indirect effect (AIE) (blue) for all model simulations due to the impact of residential combustion emission, relative to simulations where residential combustion emissions have been removed. DRE and AIE values for each simulation are detailed in Table 2.

Residential emissions result in a negative (cooling) annual mean DRE over large regions of South Asia, East Asia, subSaharan Africa, and parts of southern Europe, with values as large as $-200 \mathrm{~mW} \mathrm{~m}^{-2}$. The simulated net negative DRE in South Asia and East Asia is consistent with a previous study (Aunan et al., 2009). In contrast, over parts of Eastern Europe and the Russian Federation, North Africa, the Middle East, and Southeast Asia, residential emissions lead to a positive DRE. Residential emissions cause a negative first AIE over most regions, with values as large as $-200 \mathrm{~mW} \mathrm{~m}^{-2}$ over eastern Africa, Eastern Europe, and West Africa. Small positive AIE $\left(<40 \mathrm{~mW} \mathrm{~m}^{-2}\right)$ is simulated in the remote Southern Ocean due to reductions in CDNC as mentioned in Sect. 3.5.

Figure 15 compares the annual mean all-sky DRE and first AIE across the different model simulations (also reported in Table 2). The simulated global annual mean DRE has an uncertain sign, with our estimates between -66 and
$+85 \mathrm{~mW} \mathrm{~m}^{-2}$. The baseline simulation results in a global mean DRE of $-5 \mathrm{~mW} \mathrm{~m}^{-2}$, similar to the simulation using monthly varying emissions $\left(-8 \mathrm{~mW} \mathrm{~m}^{-2}\right)$. Our estimates differ somewhat to Kodros et al. (2015), who found a homogeneous optical mixing state produced a positive DRE of $+15 \mathrm{~mW} \mathrm{~m}^{-2}$ for biofuel emissions; however, because residential emissions differ to biofuel emissions, comparisons become problematic. We therefore assume that differences in radiative effect compared to Kodros et al. (2015) are likely dominated by differences in emissions used and differences in the optical calculation. Doubling residential carbonaceous emissions, but keeping $\mathrm{SO}_{2}$ emissions constant, results in a positive global annual mean DRE $\left(+21 \mathrm{~mW} \mathrm{~m}^{-2}\right.$ for res_ $\times 2$ and $+10 \mathrm{~mW} \mathrm{~m}^{-2}$ for res_monthly_ $\times 2$ ). This suggests that the carbonaceous (BC and $\mathrm{POM}$ ) component of residential aerosol in our model exerts a positive DRE, but this is offset by cooling from $\mathrm{SO}_{2}$ emissions. Doubling only $\mathrm{BC}$ emissions leads to a stronger positive DRE $\left(+85 \mathrm{~mW} \mathrm{~m}^{-2}\right)$, whereas negative DRE are simulated for doubling only POM $\left(-66 \mathrm{~mW} \mathrm{~m}^{-2}\right)$ or $\mathrm{SO}_{2}\left(-43 \mathrm{~mW} \mathrm{~m}^{-2}\right)$ emissions. The DRE is also sensitive to emitted particle size, resulting in positive global mean DRE of between +1 and $+63 \mathrm{~mW} \mathrm{~m}^{-2}$ when carbonaceous particles are emitted at smaller sizes (res_aero and res_small respectively). This change in sign to a positive DRE can be attributed to reduced removal rates for carbonaceous particles emitted at smaller sizes, which leads to larger BC burden, particularly in the FT where BC influence on DRE is most efficient. Residential emissions exert a negative (cooling) but uncertain global annual mean first AIE, estimated at between -502 and $-16 \mathrm{~mW} \mathrm{~m}^{-2}$. The baseline simulation results in a global mean first AIE of $-25 \mathrm{~mW} \mathrm{~m}^{-2}$, similar to the simulation using monthly varying emissions $\left(-20 \mathrm{~mW} \mathrm{~m}^{-2}\right)$. Emitting residential carbonaceous aerosol at small sizes contributes most of the uncertainly to simulated first AIE, with estimates between $-46 \mathrm{~mW} \mathrm{~m}^{-2}$ (res_aero) and $-502 \mathrm{~mW} \mathrm{~m}^{-2}$ (res_small) due to a greater increase in global CDNC. We find little sensitivity of the AIE to changes in carbonaceous emission mass: doubling carbonaceous emissions (res_ $\times 2$ ) changes 
AIE by less than $2 \mathrm{~mW} \mathrm{~m}^{-2}(\sim 10 \%)$ due to limited changes in CDNC. In contrast, doubling $\mathrm{SO}_{2}$ emissions leads to the greater negative AIE $\left(-45 \mathrm{~mW} \mathrm{~m}^{-2}\right)$ due to greater global contribution to CDNCs.

\section{Discussion and conclusions}

We used a global aerosol microphysics model (GLOMAP) to quantify the impacts of residential emissions on ambient aerosol, human health, and climate in the year 2000. We tested the sensitivity of simulated aerosol to uncertainty in emission amount and seasonal variability, emitted primary carbonaceous aerosol size distributions, and the impact of particle formation.

To evaluate model simulations we synthesised in situ observations of $\mathrm{BC}, \mathrm{OC}$, and $\mathrm{PM}_{2.5}$ concentrations and aerosol number size distribution. The baseline simulation underestimated observed $\mathrm{BC}, \mathrm{OC}$, and $\mathrm{PM}_{2.5}$ concentrations, with the largest underestimation over East Asia and South Asia, consistent with other modelling studies (Fu et al., 2012; Moorthy et al., 2013; Pan et al., 2015). Applying monthly varying emissions (MACCity emission data set), in place of annual mean emissions (ACCMIP emission), has little improvement on overall model bias but does improve the ability of the model to simulate the observed seasonal variability of aerosol. Doubling residential carbonaceous combustion emissions improved model agreement, but GLOMAP still underestimated $\mathrm{BC}, \mathrm{OC}$, and $\mathrm{PM}_{2.5}$ concentrations. The model typically had a larger underestimation of OC compared to $\mathrm{BC}$ concentrations, possibly due to uncertainty in emission factors or potentially due to an underestimation of anthropogenic SOA (Spracklen et al., 2011b).

We used source apportionment studies using ${ }^{14} \mathrm{C}$ nonfossil $\mathrm{BC}$ analysis at the island site of Hanimaadhoo in the Indian Ocean as an additional constraint of the model. Nonfossil sources have been estimated to contribute $46-73 \%$ at this location. This large range makes it difficult to constrain the model. With standard emissions (ACCMIP and MACCity), we estimate a non-fossil fraction of $57-65 \%$, whereas when residential $\mathrm{BC}$ emissions are doubled, we simulate a non-fossil fraction of $72-79 \%$.

Overall, our results suggest that residential emissions may be underestimated in the MACCity and ACCMIP data sets. Uncertainty in aerosol removal processes and transport and missing anthropogenic SOA and nitrate formation may all contribute to underestimation of aerosol mass. Nevertheless, previous modelling studies have also suggested that residential emission data sets underestimate emissions (Park et al., 2005; Koch et al., 2009; Ganguly et al., 2009; Menon et al., 2010; Bergström et al., 2012; Nair et al., 2012; Fu et al., 2012; Moorthy et al., 2013; Bond et al., 2013; Pan et al., 2015). The ACCMIP and MACCity emission data sets are constructed using national data on fuel use, which implies uniform per capita fuel consumption at the country level. Us- ing subnational fuel use data, R. Wang et al. (2014) showed that the MACCity data set underestimated residential emissions over source regions in Asia. Other studies have also had to increase residential emissions over Europe in order to match source apportionment studies (Denier van der Gon et al., 2015). However, Wang et al. (2013) suggested that model bias over China could partly be attributed to coarse model resolution and comparison against urban data and monthly mean observations. Kumar et al. (2015) also showed that a high-resolution model was able simulate reasonable BC distributions in South Asian region. We have restricted our analysis to rural and background sites but use monthly mean $\mathrm{BC}$ and $\mathrm{OC}$ data and a relatively coarse-resolution global model. To help resolve uncertainties in residential emission budget, higher-resolution emission inventories (using subnational fuel use data) and higher-resolution model simulations evaluated against long-term and high temporal resolution data are required. In many regions, observational data are lacking; there is an urgent requirement for detailed characterisation of the chemical, physical, and optical properties of aerosol in regions impacted by residential emissions, particularly in the developing world.

Particle number concentrations are generally predicted within a factor of 2 at the limited number of locations where observations are available. Simulated particle number is very sensitive to emitted particle size, which has a large uncertainty. Emitting residential carbonaceous particles at the small end of the range reported by Bond et al. (2006) (geometric mean diameter $=20 \mathrm{~nm}$ ) substantially overestimates observed particle number, suggesting this assumption is not appropriate for coarse-resolution global models.

Residential emissions contribute substantially to simulated annual mean surface PM concentrations. Greatest fractional contributions $(15$ to $>40 \%)$ to surface $\mathrm{PM}_{2.5}$ concentrations are simulated over Eastern Europe (including parts of the Russian Federation), parts of East Africa, South Asia, and East Asia. In these regions residential emissions contribute $>50 \%$ to total simulated BC and POM concentrations. These findings support previous studies suggesting a large contribution of residential emissions to $\mathrm{PM}_{2.5}$ concentrations over Asia (Venkataraman et al., 2005; Cao et al., 2006; Klimont et al., 2009; Lei et al., 2011; Cui et al., 2015; Fu et al., 2012; Gustafsson et al., 2009; B. Chen et al., 2013). Our findings suggest that reductions in residential emissions need to be considered alongside mitigation strategies for other PM sources (e.g. industry and transport) within Asia and in even more developed regions such as parts of Europe (Fountoukis et al., 2014).

We estimated the impact of residential emissions on human health due to increased ambient $\mathrm{PM}_{2.5}$ concentrations and tested the sensitivity to the emission data set and emission budget. We used a log-linear model of relative risk from the epidemiological literature (Ostro, 2004) to relate simulated changes in ambient $\mathrm{PM}_{2.5}$ concentrations to longterm excess premature mortality for cardiopulmonary dis- 
ease and lung cancer for adults ( $>30$ years of age). In the baseline simulation, we estimate that residential emissions cause 315000 (132000-508 000, 5th to 95th percentile uncertainty range) premature mortalities each year. Applying a seasonal cycle to emissions changed our estimate by less than $2 \%$, with residential emissions resulting in 308000 (113 300-497 000) premature mortalities each year. Our estimate for residential emissions is equivalent to $8 \%$ of the total mortality attributed to exposure to ambient $\mathrm{PM}_{2.5}$ from all anthropogenic sources (WHO, 2014b), although we note that methodologies in the two studies are different. Doubling residential carbonaceous emissions, which improved model comparison against observed $\mathrm{BC}$ and $\mathrm{POM}$ concentrations, increases simulated excess mortality by $\sim 64 \%$ to 516600 (192000-827 000). Simulated mortality is greatest over regions with large residential emissions and high population densities including East Asia, South Asia, Eastern Europe, and the Russian Federation. We find that half of simulated global excess mortality from residential emissions occurs in China and India alone. Our results are consistent with a previous estimate of RSF cooking emissions on premature mortality (Chafe et al., 2014). The CRFs that are used to estimate long-term premature mortality are uncertain. The loglinear function used here is based on epidemiological studies from North America (Pope III et al., 2002), resulting in greater uncertainty when these functions are extrapolated to other regions (Silva et al., 2013). However, epidemiological studies are not available for all regions, so global mortality estimates often use functions based on these North American studies. Overall, we find that uncertainty in the relationship between PM concentrations and health impacts (as quantified by the 95th percentile range given by the log-linear model) and our measure of uncertainty in emissions (estimated here as a factor of 2 uncertainty) result in comparable uncertainty in the estimated global number of premature mortalities. Future work therefore needs to improve both our understanding of residential emissions and the relationships between enhanced PM concentrations and human health impacts. We also note that the coarse resolution of our global model likely provides a conservative estimate of premature mortality due to residential emissions because it cannot simulate high concentrations associated with highly populated urban and semi-urban areas. Further simulations using higherresolution models and emission inventories will be required to accurately simulate $\mathrm{PM}_{2.5}$ concentrations in urban and semi-urban areas. Health effects using more recent CRFs that relate $\mathrm{RR}$ of disease to changes in $\mathrm{PM}_{2.5}$ over a large range of concentration exposures (Burnett et al., 2014) will also be required. In addition, exposure functions, such as the one used in this study, treat all aerosol components as equally toxic, but carbonaceous aerosol, which dominate residential emissions, may be more toxic compared to inorganic or crustal PM (Tuomisto et al., 2008). New exposure response functions will therefore need to account for the different toxicity of chemical components present in atmospheric aerosols.
We used an offline radiative transfer model to estimate the radiative effect (RE) of aerosol from residential emissions. We estimate that residential emissions exert a global annual mean DRE of between -66 and $+85 \mathrm{~mW} \mathrm{~m}^{-2}$. The simulated global mean DRE is sensitive to the amount and ratio of $\mathrm{BC}, \mathrm{POM}$, and $\mathrm{SO}_{2}$ in emissions. Doubling residential carbonaceous emissions, but keeping $\mathrm{SO}_{2}$ emissions constant, results in a positive global annual mean DRE, suggesting that the carbonaceous component of residential aerosol exerts a net positive DRE in our simulations, offset by cooling from $\mathrm{SO}_{2}$ emissions. We also find a positive DRE when primary carbonaceous emissions are emitted at smaller sizes, but this simulation overestimates observed aerosol number, suggesting it is unrealistic. Discounting this simulation, we provide a best estimate of global mean DRE due to residential combustion of between -66 and $+21 \mathrm{~mW} \mathrm{~m}^{-2}$ for the year 2000 .

Residential emissions exert a simulated global annual mean first AIE of between -502 and $-16 \mathrm{~mW} \mathrm{~m}^{-2}$. Uncertainty in emitted primary carbonaceous particle size contributes most of the uncertainly to calculated AIE. Emitting carbonaceous aerosol at smaller sizes results in greater simulated $N_{50}$ and CDNC and a strong negative AIE as well as in overestimation of observed particle number, suggesting that emission at very small sizes is not realistic. We find little sensitivity to annual mean first AIE due changes in carbonaceous emission mass compared to the baseline simulation. Doubling carbonaceous emissions changes AIE by less than $2 \mathrm{~mW} \mathrm{~m}^{-2}(\sim 10 \%)$, highlighting a non-linear relationship between magnitude of emission and first AIE. Our best estimate of the first AIE due to residential emissions is between -52 and $-16 \mathrm{~mW} \mathrm{~m}^{-2}$ in the year 2000 .

We have restricted our analysis of the RE of residential emissions to the aerosol DRE and first AIE. We treat POM aerosol as scattering, although a fraction of POM aerosol may absorb radiation (Kirchstetter et al., 2004; Chen and Bond, 2010; Arola et al., 2011; X. Wang et al., 2014). Furthermore, our DRE analysis is limited because we do not fully explore the full range of optical mixing states for residential emissions. We assume that BC is mixed homogeneously with scattering species, which provides an upper limit for BC DRE (Jacobson, 2001). A full investigation of the different optical mixing states commonly used in global models, such as in Kodros et al. (2015), would yield a better understanding of DRE from residential emissions. Because we use an offline radiative transfer model, we also do not treat cloud lifetime (second indirect effect) or semi-direct effects (Koch and Del Genio, 2010) and cannot explore additional impacts such as the weakening of the South Asia monsoon, altering of precipitation patterns (Ramanathan et al., 2005), tropical cyclone intensification (Evan et al., 2011), and accelerated melting of glaciers in the Himalayas (Xu et al., 2009).

The introduction of cleaner and fuel efficient residential combustion technologies, processed solid fuels, and clean alternative energy (e.g. natural gas, electricity) has been sug- 
gested as one of the fastest ways to reduce residential emissions (UNEP, 2011), thus slowing climate change and improving air quality and human health (WHO, 2009). Our study shows that the complete elimination of residential emissions would result in substantially improved PM air quality and human health across large regions of the world regardless of the uncertainties between the different model simulations explored here.

We have shown that residential combustion emissions exert an uncertain RE, which leads to uncertainties in predicting the climate impact of emission reductions. Our work suggests that residential emission flux, chemical composition, and carbonaceous size distributions need to be better characterised in order to constrain the likely climate impact. Given these uncertainties, the missing processes within our model framework (described above), and the use of an offline radiative transfer model, it is difficult asses the full climate impacts due to residential emissions. In addition, because we find residential emission amount and resulting RE (particularly aerosol-cloud effects) are not linearly related, our results cannot be used to estimate the impacts associated with smaller, realistic reductions in residential emissions. Future research is needed to explore the air quality and climate impact of realistic emission reductions scenarios that could potentially be achieved through the implementation of cleaner combustion technologies and clean alternative fuels.
More people are using RSF for cooking than at any other point in human history, even though the fraction of the population using these fuels is falling (Bonjour et al., 2013). Over the next few decades (2005-2030), combustion of RSF is projected to increase in South Asia and Africa due to increases in human population (UNEP, 2011). We have reported human health and climate impacts for the year 2000, but in China, residential emissions have increased $34 \%$ during the period 2000-2012 due to the growth of coal consumption (Cui et al., 2015). The use of biomass for heating is also expected to increase in developed countries such as in Western Europe because of rising fossil fuel prices and use of renewable biomass under climate change mitigation policy (Denier van der Gon et al., 2015). The impact of residential emissions on human health and climate is, therefore, likely to persist in the future unless effective mitigation to address the dependence on RSFs is taken. 


\section{Appendix A}

Table A1. Acronyms used in this study.

\begin{tabular}{ll}
\hline Acronym & Description \\
\hline ACCMIP & Atmospheric Chemistry and Climate Model Intercomparison Project \\
AF & Attributable fraction \\
AIE & Aerosol indirect effect \\
BC & Black carbon \\
BHN & Binary homogenous nucleation \\
BLN & Boundary layer nucleation \\
CCN & Cloud condensation nuclei \\
CDNC & Cloud droplet number concentration \\
CPD & Cardiopulmonary disease \\
CRF & Concentration response functions \\
DRE & Direct radiative effect \\
EC & Elemental carbon \\
FT & Free troposphere \\
LC & Lung cancer \\
LPG & Liquefied petroleum gas \\
LW & Longwave \\
MACCity & MACC/CityZEN project \\
NH & Northern Hemisphere \\
$N_{3}$ & Number of particles greater than $3 \mathrm{~nm}$ dry diameter \\
$N_{50}$ & Number of particles greater than $50 \mathrm{~nm}$ dry diameter \\
$N_{100}$ & Number of particles greater than 100 nm dry diameter \\
NMBF & Normalised mean bias factor \\
OC & Organic carbon \\
PM & Particulate matter \\
PM & Particulate matter with an aerodynamic dry diameter of $<2.5 \mu \mathrm{m}$ \\
POM & Particulate organic matter \\
RE & Radiative effect \\
RR & Relative risk \\
RSF & Residential solid fuel \\
SOA & Secondary organic aerosol \\
SW & Shortwave \\
TOA & Top of atmosphere \\
& \\
& \\
\hline
\end{tabular}


Acknowledgements. E. W. Butt acknowledges support from the United Bank of Carbon and the University of Leeds. V. Vakkari acknowledges support from the Academy of Finland Finnish Center of Excellence program (grant no. 1118615). Ambient aerosol measurements obtained through the Atmospheric Brown Cloud project funded by the United Nations Environmental Programme and the National Oceanic and Atmospheric Administration. Particulate matter sample collection, analysis, and data validation was supported by James J. Schauer at the University of WisconsinMadison, Jeff DeMinter at the Wisconsin State Laboratory of Hygiene, Soon-Chang Yoon of Seoul National University, and Pradeep Dangol and Bidya Banmali Pradhan at the International Center for Integrated Mountain Development. H. Yang would like to thank the support from National Science Foundation for Young Scholars of China (grant no. 41205003). We acknowledge funding from the Natural Environment Research Council (NERC) (grant no. NE/K015966/1).

Edited by: S. S. Gunthe

\section{References}

Adams, P. and Seinfeld, J.: Disproportionate impact of particulate emissions on global cloud condensation nuclei concentrations, Geophys. Res. Lett., 30, 1239, doi:10.1029/2002GL016303, 2003.

Adhikary, B., Carmichael, G. R., Tang, Y., Leung, L. R., Qian, Y., Schauer, J. J., Stone, E. A., Ramanathan, V., and Ramana, M. V.: Characterization of the seasonal cycle of south Asian aerosols: a regional-scale modeling analysis, J. Geophys. Res.-Atmos., 112, D22S22, doi:10.1029/2006JD008143,2007.

Allen, R. W., Gombojav, E., Barkhasragchaa, B., Byambaa, T., Lkhasuren, O., Amram, O., Takaro, T. K., and Janes, C. R.: An assessment of air pollution and its attributable mortality in Ulaanbaatar, Mongolia, Air Qual. Atmos. Health, 6, 137-150, 2013.

Andres, R. and Kasgnoc, A.: A time-averaged inventory of subaerial volcanic sulfur emissions, J. Geophys. Res.-Atmos., 103, 2525125261, 1998.

Anenberg, S. C., Horowitz, L. W., Tong, D. Q., and West, J.: An estimate of the global burden of anthropogenic ozone and fine particulate matter on premature human mortality using atmospheric modeling, Environ. Health Persp., 118, 1189-1195, 2010.

Arnold, S. R., Chipperfield, M. P., and Blitz, M. A.: A threedimensional model study of the effect of new temperature dependent quantum yields for acetone photolysis, J. Geophys. Res., 110, D22305, doi:10.1029/2005jd005998, 2005.

Arola, A., Schuster, G., Myhre, G., Kazadzis, S., Dey, S., and Tripathi, S. N.: Inferring absorbing organic carbon content from AERONET data, Atmos. Chem. Phys., 11, 215-225, doi:10.5194/acp-11-215-2011, 2011.

Aunan, K., Berntsen, T. K., Myhre, G., Rypdal, K., Streets, D. G., Woo, J.-H., and Smith, K. R.: Radiative forcing from household fuel burning in Asia, Atmos. Environ., 43, 5674-5681, 2009.

Barahona, D., West, R. E. L., Stier, P., Romakkaniemi, S., Kokkola, H., and Nenes, A.: Comprehensively accounting for the effect of giant $\mathrm{CCN}$ in cloud activation parameterizations, Atmos. Chem. Phys., 10, 2467-2473, doi:10.5194/acp-10-24672010, 2010.
Bauer, S. E., Menon, S., Koch, D., Bond, T. C., and Tsigaridis, K.: A global modeling study on carbonaceous aerosol microphysical characteristics and radiative effects, Atmos. Chem. Phys., 10, 7439-7456, doi:10.5194/acp-10-7439-2010, 2010.

Bellouin, N., Rae, J., Jones, A., Johnson, C., Haywood, J., and Boucher, O.: Aerosol forcing in the Climate Model Intercomparison Project (CMIP5) simulations by HadGEM2-ES and the role of ammonium nitrate, J. Geophys. Res.-Atmos., 116, D20206, doi:10.1029/2011JD016074, 2011.

Bellouin, N., Mann, G. W., Woodhouse, M. T., Johnson, C., Carslaw, K. S., and Dalvi, M.: Impact of the modal aerosol scheme GLOMAP-mode on aerosol forcing in the Hadley Centre Global Environmental Model, Atmos. Chem. Phys., 13, 30273044, doi:10.5194/acp-13-3027-2013, 2013.

Bergström, R., Denier van der Gon, H. A. C., Prévôt, A. S. H., Yttri, K. E., and Simpson, D.: Modelling of organic aerosols over Europe (2002-2007) using a volatility basis set (VBS) framework: application of different assumptions regarding the formation of secondary organic aerosol, Atmos. Chem. Phys., 12, 8499-8527, doi:10.5194/acp-12-8499-2012, 2012.

Bond, T. C., Streets, D. G., Yarber, K. F., Nelson, S. M., Woo, J.-H., and Klimont, Z.: A technology-based global inventory of black and organic carbon emissions from combustion, J. Geophys. Res., 109, D14203, doi:10.1029/2003jd003697, 2004.

Bond, T. C., Habib, G., and Bergstrom, R. W.: Limitations in the enhancement of visible light absorption due to mixing state, J. Geophys. Res., 111, D20211, doi:10.1029/2006JD007315, 2006.

Bond, T. C., Bhardwaj, E., Dong, R., Jogani, R., Jung, S., Roden, C., Streets, D. G., and Trautmann, N. M.: Historical emissions of black and organic carbon aerosol from energy-related combustion, 1850-2000, Global Biogeochem. Cy., 21, GB2018, doi:10.1029/2006GB002840, 2007.

Bond, T. C., Doherty, S. J., Fahey, D., Forster, P., Berntsen, T., DeAngelo, B., Flanner, M., Ghan, S., Kärcher, B., and Koch, D.: Bounding the role of black carbon in the climate system: a scientific assessment, J. Geophys. Res.-Atmos., 118, 5380-5552, 2013.

Bonjour, S., Adair-Rohani, H., Wolf, J., Bruce, N. G., Mehta, S., Pruss-Ustun, A., Lahiff, M., Rehfuess, E. A., Mishra, V., and Smith, K. R.: Solid fuel use for household cooking: country and regional estimates for 1980-2010, Environ. Health Persp., 121, 784-790, 2013.

Bosch, C., Andersson, A., Kirillova, E. N., Budhavant, K., Tiwari, S., Praveen, P., Russell, L. M., Beres, N. D., Ramanathan, V., and Gustafsson, Ö.: Source-diagnostic dual-isotope composition and optical properties of water-soluble organic carbon and elemental carbon in the South Asian outflow intercepted over the Indian Ocean, J. Geophys. Res.-Atmos., 119, 11743-11759, 2014.

Boucher, O., Randall, D., Artaxo, P., Bretherton, C., Feingold, G., Forster, P., Kerminen, V.-M., Kondo, Y., Liao, H., and Lohmann, U.: Clouds and aerosols, in: Climate Change 2013: The Physical Science Basis, Contribution of working group I to the fifth assessment report of the intergovernmental panel on climate change, Cambridge University Press, Cambridge, UK, and New York, NY, USA, 571-657, 2013.

Brook, R. D., Rajagopalan, S., Pope, C. A., Brook, J. R., Bhatnagar, A., Diez-Roux, A. V., Holguin, F., Hong, Y., Luepker, R. V., and Mittleman, M. A.: Particulate matter air pollution and cardiovascular disease an update to the scientific statement from 
the American Heart Association, Circulation, 121, 2331-2378, 2010.

Browse, J., Carslaw, K. S., Arnold, S. R., Pringle, K., and Boucher, O.: The scavenging processes controlling the seasonal cycle in Arctic sulphate and black carbon aerosol, Atmos. Chem. Phys., 12, 6775-6798, doi:10.5194/acp-12-6775-2012, 2012.

Burnett, R. T., Pope, C. A., Ezzati, M., Olives, C., Lim, S. S., Mehta, S., Shin, H. H., Singh, G., Hubbell, B., and Brauer, M.: An integrated risk function for estimating the global burden of disease attributable to ambient fine particulate matter exposure, Environ. Health Perspect., 122, 397-403, doi:10.1289/ehp.1307049, 2014

Cao, G., Zhang, X., and Zheng, F.: Inventory of black carbon and organic carbon emissions from China, Atmos. Environ., 40, 6516$6527,2006$.

Chafe, Z. A., Brauer, M., Klimont, Z., Van Dingenen, R., Mehta, S., Rao, S., Riahi, K., Dentener, F., and Smith, K. R.: Household cooking with solid fuels contributes to ambient $\mathrm{PM}_{2.5}$ air pollution and the Burden of Disease, Environ. Health Perspect., 122, 1314-1320, 2014.

Chen, B., Andersson, A., Lee, M., Kirillova, E. N., Xiao, Q., Kruså, M., Shi, M., Hu, K., Lu, Z., and Streets, D. G.: Source forensics of black carbon aerosols from China, Environ. Sci. Technol., 47, 9102-9108, 2013.

Chen, Y. and Bond, T. C.: Light absorption by organic carbon from wood combustion, Atmos. Chem. Phys., 10, 1773-1787, doi:10.5194/acp-10-1773-2010, 2010.

Chen, Y., Sheng, G., Bi, X., Feng, Y., Mai, B., and Fu, J.: Emission factors for carbonaceous particles and polycyclic aromatic hydrocarbons from residential coal combustion in China, Environ. Sci. Technol., 39, 1861-1867, 2005.

Chen, Y., Zhi, G., Feng, Y., Fu, J., Feng, J., Sheng, G., and Simoneit, B. R.: Measurements of emission factors for primary carbonaceous particles from residential raw-coal combustion in China, Geophys. Res. Lett., 33, L20815, doi:10.1029/2006GL026966, 2006.

Chen, Y., Ebenstein, A., Greenstone, M., and Li, H.: Evidence on the impact of sustained exposure to air pollution on life expectancy from China's Huai River policy, P. Natl. Acad. Sci. USA, 110, 12936-12941, 2013.

Chipperfield, M.: New version of the TOMCAT/SLIMCAT offline chemical transport model: intercomparison of stratospheric tracer experiments, Q. J. Roy. Meteorol. Soc., 132, 1179-1203, 2006.

Cohen, A. J., Anderson, H. R., Ostro, B., Pandey, K. D., Krzyzanowski, M., Künzli, N., Gutschmidt, K., Pope III, C. A., Romieu, I., and Samet, J. M.: Urban air pollution, Comparative Quantification of Health Risks, 2, 1353-1433, 2004.

Cohen, A. J., Anderson, H. R., Ostro, B., Pandey, K. D., Krzyzanowski, M., Künzli, N., Gutschmidt, K., Pope III, C. A., Romieu, I., and Samet, J. M.: The global burden of disease due to outdoor air pollution, J. Toxicol. Env. Heal. A, 68, 1301-1307, 2005

Cui, H., Mao, P., Zhao, Y., Nielsen, C. P., and Zhang, J.: Patterns in atmospheric carbonaceous aerosols in China: emission estimates and observed concentrations, Atmos. Chem. Phys., 15, 86578678, doi:10.5194/acp-15-8657-2015, 2015.

Denier van der Gon, H. A. C., Bergström, R., Fountoukis, C., Johansson, C., Pandis, S. N., Simpson, D., and Viss- chedijk, A. J. H.: Particulate emissions from residential wood combustion in Europe - revised estimates and an evaluation, Atmos. Chem. Phys., 15, 6503-6519, doi:10.5194/acp-15-65032015, 2015.

Dentener, F., Kinne, S., Bond, T., Boucher, O., Cofala, J., Generoso, S., Ginoux, P., Gong, S., Hoelzemann, J. J., Ito, A., Marelli, L., Penner, J. E., Putaud, J.-P., Textor, C., Schulz, M., van der Werf, G. R., and Wilson, J.: Emissions of primary aerosol and precursor gases in the years 2000 and 1750 prescribed data-sets for AeroCom, Atmos. Chem. Phys., 6, 43214344, doi:10.5194/acp-6-4321-2006, 2006.

Dusek, U., Frank, G., Hildebrandt, L., Curtius, J., Schneider, J., Walter, S., Chand, D., Drewnick, F., Hings, S., and Jung, D.: Size matters more than chemistry for cloud-nucleating ability of aerosol particles, Science, 312, 1375-1378, 2006.

Edwards, J. and Slingo, A.: Studies with a flexible new radiation code. I: Choosing a configuration for a large-scale model, Q. J. Roy. Meteorol. Soc., 122, 689-719, 1996.

EEA: European Union emission inventory report, 1990-2012 under the UNECE Convention on Long-range Transboundary Air Pollution (LRTAP), EEA (European Environment Agency), Copenhagen, 2014.

Evan, A. T., Kossin, J. P., and Ramanathan, V.: Arabian Sea tropical cyclones intensified by emissions of black carbon and other aerosols, Nature, 479, 94-97, 2011.

Forster, P., Ramaswamy, V., Artaxo, P., Berntsen, T., Betts, R., Fahey, D. W., Haywood, J., Lean, J., Lowe, D. C., Myhre, G., Nganga, J., Prinn, R., Raga, G., Schulz, M., and Dorland, R. V.: Changes in Atmospheric Constituents and in Radiative Forcing, in: Climate Change 2007: The Physical Science Basis, Contribution of Working Group I to the Fourth Assessment Report of the Intergovernmental Panel on Climate Change, edited by: Solomon, S., Qin, D., Manning, M., Chen, Z., Marquis, M., Averyt, K. B., Tignor, M., and Miller, H. L., Cambridge University Press, Cambridge, UK, and New York, USA, 2007.

Fountoukis, C. and Nenes, A.: Continued development of a cloud droplet formation parameterization for global climate models, J. Geophys. Res.-Atmos., 110, D11212, doi:10.1029/2004jd005591, 2005.

Fountoukis, C., Butler, T., Lawrence, M., van der Gon, H. D., Visschedijk, A., Charalampidis, P., Pilinis, C., and Pandis, S.: Impacts of controlling biomass burning emissions on wintertime carbonaceous aerosol in Europe, Atmos. Environ., 87, 175-182, 2014.

Fu, T.-M., Cao, J. J., Zhang, X. Y., Lee, S. C., Zhang, Q., Han, Y. M., Qu, W. J., Han, Z., Zhang, R., Wang, Y. X., Chen, D., and Henze, D. K.: Carbonaceous aerosols in China: top-down constraints on primary sources and estimation of secondary contribution, Atmos. Chem. Phys., 12, 2725-2746, doi:10.5194/acp12-2725-2012, 2012.

Fuller, K. A., Malm, W. C., and Kreidenweis, S. M.: Effects of mixing on extinction by carbonaceous particles, J. Geophys. Res.Atmos., 104, 15941-15954, 1999.

Ganguly, D., Ginoux, P., Ramaswamy, V., Winker, D., Holben, B., and Tripathi, S.: Retrieving the composition and concentration of aerosols over the Indo-Gangetic basin using CALIOP and AERONET data, Geophys. Res. Lett., 36, L13806, doi:10.1029/2009GL038315, 2009.

Giannadaki, D., Pozzer, A., and Lelieveld, J.: Modeled global effects of airborne desert dust on air quality and premature mortal- 
ity, Atmos. Chem. Phys., 14, 957-968, doi:10.5194/acp-14-9572014, 2014.

Gong, S.: A parameterization of sea-salt aerosol source function for sub- and super-micron particles, Global Biogeochem. Cy., 17, 1097, doi:10.1029/2003gb002079, 2003.

Granier, C., Bessagnet, B., Bond, T., D’Angiola, A., Van Der Gon, H. D., Frost, G. J., Heil, A., Kaiser, J. W., Kinne, S., and Klimont, Z.: Evolution of anthropogenic and biomass burning emissions of air pollutants at global and regional scales during the 1980-2010 period, Climatic Change, 109, 163-190, 2011.

Guenther, A., Hewitt, C. N., Erickson, D., Fall, R., Geron, C., Graedel, T., Harley, P., Klinger, L., Lerdau, M., McKay, W. A., Pierce, T., Scholes, B., Steinbrecher, R., Tallamraju, R., Taylor, J., and Zimmerman, P.: A global model of natural volatile organic compound emissions, J. Geophys. Res., 100, 8873-8892, doi:10.1029/94jd02950, 1995.

Gustafsson, Ö., Kruså, M., Zencak, Z., Sheesley, R. J., Granat, L., Engström, E., Praveen, P., Rao, P., Leck, C., and Rodhe, H.: Brown clouds over South Asia: biomass or fossil fuel combustion?, Science, 323, 495-498, 2009.

Halmer, M. M., Schmincke, H. U., and Graf, H. F.: The annual volcanic gas input into the atmosphere, in particular into the stratosphere: a global data set for the past 100 years, J. Volcanol. Geoth. Res., 115, 511-528, doi:10.1016/s0377-0273(01)003183, 2002.

Han, Z., Zhang, R., Wang, Q. G., Wang, W., Cao, J., and $\mathrm{Xu}, \mathrm{J} .:$ Regional modeling of organic aerosols over China in summertime, J. Geophys. Res.-Atmos., 113, D11202, doi:10.1029/2007JD009436, 2008.

Jacobson, M. Z.: Strong radiative heating due to the mixing state of black carbon in atmospheric aerosols, Nature, 409, 695-697, 2001.

Jacobson, M. Z.: Short-term effects of controlling fossil-fuel soot, biofuel soot and gases, and methane on climate, Arctic ice, and air pollution health, J. Geophys. Res.-Atmos., 115, D14209, doi:10.1029/2009JD013795, 2010.

Johnson, M., Edwards, R., Alatorre Frenk, C., and Masera, O.: Infield greenhouse gas emissions from cookstoves in rural Mexican households, Atmos. Environ., 42, 1206-1222, 2008.

Johnston, F. H., Henderson, S. B., Chen, Y., Randerson, J. T., Marlier, M., DeFries, R. S., Kinney, P., Bowman, D. M., and Brauer, M.: Estimated global mortality attributable to smoke from landscape fires, Environ. Health Persp., 120, 695-701, 2012.

Johnston, F. H., Hanigan, I. C., Henderson, S. B., and Morgan, G. G.: Evaluation of interventions to reduce air pollution from biomass smoke on mortality in Launceston, Australia: retrospective analysis of daily mortality, 1994-2007, Brit. Med. J., 346, e8446, doi:10.1136/bmj.e8446, 2013.

Kettle, A. and Andreae, M.: Flux of dimethylsulfide from the oceans: a comparison of updated data sets and flux models, J. Geophys. Res.-Atmos., 105, 26793-26808, 2000.

Kirchstetter, T. W., Novakov, T., and Hobbs, P. V.: Evidence that the spectral dependence of light absorption by aerosols is affected by organic carbon, J. Geophys. Res.-Atmos., 109, D21208, doi:10.1029/2004JD004999, 2004.

Kirillova, E. N., Andersson, A., Sheesley, R. J., Kruså, M., Praveen, P., Budhavant, K., Safai, P., Rao, P., and Gustafsson, Ö.: 13Cand, 14C-based study of sources and atmospheric process- ing of water-soluble organic carbon (WSOC) in South Asian aerosols, J. Geophys. Res.-Atmos., 118, 614-626, 2013.

Klimont, Z., Cofala, J., Xing, J., Wei, W., Zhang, C., Wang, S., Kejun, J., Bhandari, P., Mathur, R., and Purohit, P.: Projections of $\mathrm{SO}_{2}, \mathrm{NO}_{x}$ and carbonaceous aerosols emissions in Asia, Tellus B, 61, 602-617, 2009.

Koch, D. and Del Genio, A. D.: Black carbon semi-direct effects on cloud cover: review and synthesis, Atmos. Chem. Phys., 10, 7685-7696, doi:10.5194/acp-10-7685-2010, 2010.

Koch, D., Schulz, M., Kinne, S., McNaughton, C., Spackman, J. R., Balkanski, Y., Bauer, S., Berntsen, T., Bond, T. C., Boucher, O., Chin, M., Clarke, A., De Luca, N., Dentener, F., Diehl, T., Dubovik, O., Easter, R., Fahey, D. W., Feichter, J., Fillmore, D., Freitag, S., Ghan, S., Ginoux, P., Gong, S., Horowitz, L., Iversen, T., Kirkevåg, A., Klimont, Z., Kondo, Y., Krol, M., Liu, X., Miller, R., Montanaro, V., Moteki, N., Myhre, G., Penner, J. E., Perlwitz, J., Pitari, G., Reddy, S., Sahu, L., Sakamoto, H., Schuster, G., Schwarz, J. P., Seland, Ø., Stier, P., Takegawa, N., Takemura, T., Textor, C., van Aardenne, J. A., and Zhao, Y.: Evaluation of black carbon estimations in global aerosol models, Atmos. Chem. Phys., 9, 9001-9026, doi:10.5194/acp-9-9001-2009, 2009.

Kodros, J. K., Scott, C. E., Farina, S. C., Lee, Y. H., L'Orange, C., Volckens, J., and Pierce, J. R.: Uncertainties in global aerosols and climate effects due to biofuel emissions, Atmos. Chem. Phys., 15, 8577-8596, doi:10.5194/acp-15-8577-2015, 2015.

Kulmala, M., Laaksonen, A., and Pirjola, L.: Parameterizations for sulfuric acid/water nucleation rates, J. Geophys. Res.-Atmos., 103, 8301-8307, 1998.

Kulmala, M., Lehtinen, K. E. J., and Laaksonen, A.: Cluster activation theory as an explanation of the linear dependence between formation rate of $3 \mathrm{~nm}$ particles and sulphuric acid concentration, Atmos. Chem. Phys., 6, 787-793, doi:10.5194/acp-6-787-2006, 2006.

Kumar, R., Barth, M. C., Nair, V. S., Pfister, G. G., Suresh Babu, S., Satheesh, S. K., Krishna Moorthy, K., Carmichael, G. R., Lu, Z., and Streets, D. G.: Sources of black carbon aerosols in South Asia and surrounding regions during the Integrated Campaign for Aerosols, Gases and Radiation Budget (ICARB), Atmos. Chem. Phys., 15, 5415-5428, doi:10.5194/acp-15-5415-2015, 2015.

Lam, N. L., Chen, Y., Weyant, C., Venkataraman, C., Sadavarte, P., Johnson, M. A., Smith, K. R., Brem, B. T., Arineitwe, J., and Ellis, J. E.: Household light makes global heat: high black carbon emissions from kerosene wick lamps, Environ. Sci. Technol., 46, 13531-13538, 2012.

Lamarque, J.-F., Bond, T. C., Eyring, V., Granier, C., Heil, A., Klimont, Z., Lee, D., Liousse, C., Mieville, A., Owen, B., Schultz, M. G., Shindell, D., Smith, S. J., Stehfest, E., Van Aardenne, J., Cooper, O. R., Kainuma, M., Mahowald, N., McConnell, J. R., Naik, V., Riahi, K., and van Vuuren, D. P.: Historical (1850-2000) gridded anthropogenic and biomass burning emissions of reactive gases and aerosols: methodology and application, Atmos. Chem. Phys., 10, 7017-7039, doi:10.5194/acp10-7017-2010, 2010.

Lei, Y., Zhang, Q., He, K. B., and Streets, D. G.: Primary anthropogenic aerosol emission trends for China, 1990-2005, Atmos. Chem. Phys., 11, 931-954, doi:10.5194/acp-11-931-2011, 2011. 
Li, X., Wang, S., Duan, L., Hao, J., and Nie, Y.: Carbonaceous aerosol emissions from household biofuel combustion in China, Environ. Sci. Technol., 43, 6076-6081, 2009.

Lim, S. S., Vos, T., Flaxman, A. D., et al.: A comparative risk assessment of burden of disease and injury attributable to 67 risk factors and risk factor clusters in, 21 regions, 1990-2010: a systematic analysis for the Global Burden of Disease Study 2010, Lancet, 380, 2224-2260, 2012.

Lu, Z., Zhang, Q., and Streets, D. G.: Sulfur dioxide and primary carbonaceous aerosol emissions in China and India, 1996-2010, Atmos. Chem. Phys., 11, 9839-9864, doi:10.5194/acp-11-98392011, 2011.

Mann, G. W., Carslaw, K. S., Spracklen, D. V., Ridley, D. A., Manktelow, P. T., Chipperfield, M. P., Pickering, S. J., and Johnson, C. E.: Description and evaluation of GLOMAP-mode: a modal global aerosol microphysics model for the UKCA composition-climate model, Geosci. Model Dev., 3, 519-551, doi:10.5194/gmd-3-519-2010, 2010.

Marlier, M. E., DeFries, R. S., Voulgarakis, A., Kinney, P. L., Randerson, J. T., Shindell, D. T., Chen, Y., and Faluvegi, G.: El Nino and health risks from landscape fire emissions in southeast Asia, Nat. Clim. Change, 3, 131-136, 2013.

Mathers, C., Fat, D. M., and Boerma, J.: The Global Burden of Disease: 2004 Update, World Health Organization, Switzerland, 2008.

Menon, S., Koch, D., Beig, G., Sahu, S., Fasullo, J., and Orlikowski, D.: Black carbon aerosols and the third polar ice cap, Atmos. Chem. Phys., 10, 4559-4571, doi:10.5194/acp-10-45592010, 2010.

Merikanto, J., Spracklen, D. V., Pringle, K. J., and Carslaw, K. S.: Effects of boundary layer particle formation on cloud droplet number and changes in cloud albedo from 1850 to 2000, Atmos. Chem. Phys., 10, 695-705, doi:10.5194/acp-10-695-2010, 2010.

Moorthy, K. K., Beegum, S. N., Srivastava, N., Satheesh, S., Chin, M., Blond, N., Babu, S. S., and Singh, S.: Performance evaluation of chemistry transport models over India, Atmos. Environ., 71, 210-225, 2013.

Nair, V. S., Solmon, F., Giorgi, F., Mariotti, L., Babu, S. S., and Moorthy, K. K.: Simulation of South Asian aerosols for regional climate studies, J. Geophys. Res.-Atmos., 117, D04209, doi:10.1029/2011JD016711, 2012.

Nenes, A. and Seinfeld, J. H.: Parameterization of cloud droplet formation in global climate models, J. Geophys. Res.-Atmos., 108, 4415, doi:10.1029/2002JD002911, 2003.

Nightingale, P. D., Malin, G., Law, C. S., Watson, A. J., Liss, P. S., Liddicoat, M. I., Boutin, J., and Upstill-Goddard, R. C.: In situ evaluation of air-sea gas exchange parameterizations using novel conservative and volatile tracers, Global Biogeochem. Cy., 14, 373-387, 2000.

Ostro, B.: Outdoor air pollution: Assessing the environmental burden of disease at national and local levels, WHO Environmental Burden of Disease Series No. 5, WHO, Geneva, 2004.

Pagels, J., Dutcher, D. D., Stolzenburg, M. R., McMurry, P. H., Gälli, M. E., and Gross, D. S.: Fine-particle emissions from solid biofuel combustion studied with single-particle mass spectrometry: identification of markers for organics, soot, and ash components, J. Geophys. Res.-Atmos., 118, 859-870, 2013.

Pan, X., Chin, M., Gautam, R., Bian, H., Kim, D., Colarco, P. R., Diehl, T. L., Takemura, T., Pozzoli, L., Tsigaridis, K., Bauer,
S., and Bellouin, N.: A multi-model evaluation of aerosols over South Asia: common problems and possible causes, Atmos. Chem. Phys., 15, 5903-5928, doi:10.5194/acp-15-5903-2015, 2015.

Parashar, D., Gadi, R., Mandal, T., and Mitra, A.: Carbonaceous aerosol emissions from India, Atmos. Environ., 39, 7861-7871, 2005.

Park, R. J., Jacob, D. J., Palmer, P. I., Clarke, A. D., Weber, R. J., Zondlo, M. A., Eisele, F. L., Bandy, A. R., Thornton, D. C., and Sachse, G. W.: Export efficiency of black carbon aerosol in continental outflow: global implications, J. Geophys. Res.-Atmos., 110, D11205, doi:10.1029/2004JD005432, 2005.

Partanen, A. I., Laakso, A., Schmidt, A., Kokkola, H., Kuokkanen, T., Pietikäinen, J.-P., Kerminen, V.-M., Lehtinen, K. E. J., Laakso, L., and Korhonen, H.: Climate and air quality tradeoffs in altering ship fuel sulfur content, Atmos. Chem. Phys., 13, 12059-12071, doi:10.5194/acp-13-12059-2013, 2013.

Penner, J. E., Andreae, M., Annegarn, H., Barrie, L., Feichter, J., Hegg, D., Jayaraman, A., Leaitch, R., Murphy, D., Nganga, J., and Pitari, G.: Aerosols, their Direct and Indirect Effects, in: Climate Change 2001: The Physical Science Basis, Contribution of Working Group I to the Third Assessment Report of the Intergovernmental Panel on Climate Change, edited by: Houghton, J. T., Ding, Y., Griggs, D. J., Noguer, M., van der Linden, P. J., Dai, X., Maskell, K., and Johnson, C. A., Cambridge University Press, Cambridge, UK, and New York, USA, 2001.

Pierce, J. R. and Adams, P. J.: Uncertainty in global CCN concentrations from uncertain aerosol nucleation and primary emission rates, Atmos. Chem. Phys., 9, 1339-1356, doi:10.5194/acp-91339-2009, 2009.

Pierce, J. R., Chen, K., and Adams, P. J.: Contribution of primary carbonaceous aerosol to cloud condensation nuclei: processes and uncertainties evaluated with a global aerosol microphysics model, Atmos. Chem. Phys., 7, 5447-5466, doi:10.5194/acp-75447-2007, 2007.

Pierce, J. R., Theodoritsi, G., Adams, P., and Pandis, S.: Parameterization of the effect of sub-grid scale aerosol dynamics on aerosol number emission rates, J. Aerosol Sci., 40, 385-393, 2009.

Pope III, C. A. and Dockery, D. W.: Health effects of fine particulate air pollution: lines that connect, JAPCA J. Air Waste Manage., 56, 709-742, 2006.

Pope III, C. A., Burnett, R. T., Thun, M. J., Calle, E. E., Krewski, D., Ito, K., and Thurston, G. D.: Lung cancer, cardiopulmonary mortality, and long-term exposure to fine particulate air pollution, Jama, 287, 1132-1141, 2002.

Pringle, K. J., Carslaw, K. S., Spracklen, D. V., Mann, G. M., and Chipperfield, M. P.: The relationship between aerosol and cloud drop number concentrations in a global aerosol microphysics model, Atmos. Chem. Phys., 9, 4131-4144, doi:10.5194/acp-94131-2009, 2009.

Pringle, K. J., Carslaw, K. S., Fan, T., Mann, G. W., Hill, A., Stier, P., Zhang, K., and Tost, H.: A multi-model assessment of the impact of sea spray geoengineering on cloud droplet number, Atmos. Chem. Phys., 12, 11647-11663, doi:10.5194/acp-1211647-2012, 2012.

Qu, W. J., Zhang, X. Y., Arimoto, R., Wang, D., Wang, Y. Q., Yan, L. W., and Li, Y.: Chemical composition of the background aerosol at two sites in southwestern and northwestern China: po- 
tential influences of regional transport, Tellus B, 60, 657-673, 2008.

Ramanathan, V. and Carmichael, G.: Global and regional climate changes due to black carbon, Nat. Geosci., 1, 221-227, 2008.

Ramanathan, V., Chung, C., Kim, D., Bettge, T., Buja, L., Kiehl, J., Washington, W., Fu, Q., Sikka, D., and Wild, M.: Atmospheric brown clouds: impacts on South Asian climate and hydrological cycle, P. Natl. Acad. Sci. USA, 102, 5326-5333, 2005.

Rap, A., Scott, C. E., Spracklen, D. V., Bellouin, N., Forster, P. M., Carslaw, K. S., Schmidt, A., and Mann, G.: Natural aerosol direct and indirect radiative effects, Geophys. Res. Lett., 40, $3297-$ 3301, 2013.

Reddington, C. L., Carslaw, K. S., Spracklen, D. V., Frontoso, M. G., Collins, L., Merikanto, J., Minikin, A., Hamburger, T., Coe, H., Kulmala, M., Aalto, P., Flentje, H., PlassDülmer, C., Birmili, W., Wiedensohler, A., Wehner, B., Tuch, T., Sonntag, A., O’Dowd, C. D., Jennings, S. G., Dupuy, R., Baltensperger, U., Weingartner, E., Hansson, H.-C., Tunved, P., Laj, P., Sellegri, K., Boulon, J., Putaud, J.-P., Gruening, C., Swietlicki, E., Roldin, P., Henzing, J. S., Moerman, M., Mihalopoulos, N., Kouvarakis, G., Ždímal, V., Zíková, N., Marinoni, A., Bonasoni, P., and Duchi, R.: Primary versus secondary contributions to particle number concentrations in the European boundary layer, Atmos. Chem. Phys., 11, 12007-12036, doi:10.5194/acp11-12007-2011, 2011.

Reddington, C. L., McMeeking, G., Mann, G. W., Coe, H., Frontoso, M. G., Liu, D., Flynn, M., Spracklen, D. V., and Carslaw, K. S.: The mass and number size distributions of black carbon aerosol over Europe, Atmos. Chem. Phys., 13, 4917-4939, doi:10.5194/acp-13-4917-2013, 2013.

Reddington, C. L., Butt, E. W., Ridley, D. A., Artaxo, P., Morgan, W. T., Coe, H., and Spracklen, D. V.: Air quality and human health improvements from reductions in deforestation-related fire in Brazil, Nat. Geosci., 8, 768-771, 2015.

Roden, C. A., Bond, T. C., Conway, S., and Pinel, A. B. O.: Emission factors and real-time optical properties of particles emitted from traditional wood burning cookstoves, Environ. Sci. Technol., 40, 6750-6757, 2006.

Roden, C. A., Bond, T. C., Conway, S., Osorto Pinel, A. B., MacCarty, N., and Still, D.: Laboratory and field investigations of particulate and carbon monoxide emissions from traditional and improved cookstoves, Atmos. Environ., 43, 1170-1181, 2009.

Rossow, W. B. and Schiffer, R. A.: Advances in understanding clouds from ISCCP, B. Am. Meteorol. Soc., 80, 2261-2287, 1999.

Schlesinger, R., Kunzli, N., Hidy, G., Gotschi, T., and Jerrett, M.: The health relevance of ambient particulate matter characteristics: coherence of toxicological and epidemiological inferences, Inhal. Toxicol., 18, 95-125, 2006.

Schmidt, A., Ostro, B., Carslaw, K. S., Wilson, M., Thordarson, T., Mann, G. W., and Simmons, A. J.: Excess mortality in Europe following a future Laki-style Icelandic eruption, P. Natl. Acad. Sci. USA, 108, 15710-15715, 2011.

Schmidt, A., Carslaw, K. S., Mann, G. W., Rap, A., Pringle, K. J., Spracklen, D. V., Wilson, M., and Forster, P. M.: Importance of tropospheric volcanic aerosol for indirect radiative forcing of climate, Atmos. Chem. Phys., 12, 7321-7339, doi:10.5194/acp-127321-2012, 2012.
Scott, C. E., Rap, A., Spracklen, D. V., Forster, P. M., Carslaw, K. S., Mann, G. W., Pringle, K. J., Kivekäs, N., Kulmala, M., Lihavainen, H., and Tunved, P.: The direct and indirect radiative effects of biogenic secondary organic aerosol, Atmos. Chem. Phys., 14, 447-470, doi:10.5194/acp-14-447-2014, 2014.

SEDAC: Sociodemographic Data and Applications Centre, Gridded Population of the World (GPW), v3., available at: http: //sedac.ciesin.columbia.edu/data/collection/gpw-v3 (last acces: 1 November 2013), 2004.

Sheesley, R. J., Kirillova, E., Andersson, A., Kruså, M., Praveen, P., Budhavant, K., Safai, P. D., Rao, P., and Gustafsson, Ö.: Yearround radiocarbon-based source apportionment of carbonaceous aerosols at two background sites in South Asia. J. Geophys. Res.Atmos., 117, D10202, doi:10.1029/2011JD017161, 2012.

Shen, G., Wang, W., Yang, Y., Zhu, C., Min, Y., Xue, M., Ding, J., Li, W., Wang, B., and Shen, H.: Emission factors and particulate matter size distribution of polycyclic aromatic hydrocarbons from residential coal combustions in rural Northern China, Atmos. Environ., 44, 5237-5243, 2010.

Sihto, S.-L., Kulmala, M., Kerminen, V.-M., Dal Maso, M., Petäjä, T., Riipinen, I., Korhonen, H., Arnold, F., Janson, R., Boy, M., Laaksonen, A., and Lehtinen, K. E. J.: Atmospheric sulphuric acid and aerosol formation: implications from atmospheric measurements for nucleation and early growth mechanisms, Atmos. Chem. Phys., 6, 4079-4091, doi:10.5194/acp-64079-2006, 2006.

Silva, R. A., West, J. J., Zhang, Y., Anenberg, S. C., Lamarque, J.-F., Shindell, D. T., Collins, W. J., Dalsoren, S., Faluvegi, G., and Folberth, G.: Global premature mortality due to anthropogenic outdoor air pollution and the contribution of past climate change, Environ. Res. Lett., 8, 034005, doi:10.1088/17489326/8/3/034005, 2013.

Smith, K. R., Bruce, N., Balakrishnan, K., Adair-Rohani, H., Balmes, J., Chafe, Z., Dherani, M., Hosgood, H. D., Mehta, S., and Pope, D.: Millions dead: how do we know and what does it mean? Methods used in the comparative risk assessment of household air pollution, Annu. Rev. Publ. Health, 35, 185-206, 2014.

Spracklen, D. V., Pringle, K. J., Carslaw, K. S., Chipperfield, M. P., and Mann, G. W.: A global off-line model of size-resolved aerosol microphysics: I. Model development and prediction of aerosol properties, Atmos. Chem. Phys., 5, 2227-2252, doi:10.5194/acp-5-2227-2005, 2005a.

Spracklen, D. V., Pringle, K. J., Carslaw, K. S., Chipperfield, M. P., and Mann, G. W.: A global off-line model of size-resolved aerosol microphysics: II. Identification of key uncertainties, Atmos. Chem. Phys., 5, 3233-3250, doi:10.5194/acp-5-3233-2005, 2005b.

Spracklen, D. V., Carslaw, K. S., Kulmala, M., Kerminen, V.-M., Mann, G. W., and Sihto, S.-L.: The contribution of boundary layer nucleation events to total particle concentrations on regional and global scales, Atmos. Chem. Phys., 6, 5631-5648, doi:10.5194/acp-6-5631-2006, 2006.

Spracklen, D. V., Carslaw, K. S., Pöschl, U., Rap, A., and Forster, P. M.: Global cloud condensation nuclei influenced by carbonaceous combustion aerosol, Atmos. Chem. Phys., 11, 9067-9087, doi:10.5194/acp-11-9067-2011, 2011a.

Spracklen, D. V., Jimenez, J. L., Carslaw, K. S., Worsnop, D. R., Evans, M. J., Mann, G. W., Zhang, Q., Canagaratna, M. R., 
Allan, J., Coe, H., McFiggans, G., Rap, A., and Forster, P.: Aerosol mass spectrometer constraint on the global secondary organic aerosol budget, Atmos. Chem. Phys., 11, 12109-12136, doi:10.5194/acp-11-12109-2011, 2011 b.

Stier, P., Feichter, J., Kinne, S., Kloster, S., Vignati, E., Wilson, J., Ganzeveld, L., Tegen, I., Werner, M., Balkanski, Y., Schulz, M., Boucher, O., Minikin, A., and Petzold, A.: The aerosol-climate model ECHAM5-HAM, Atmos. Chem. Phys., 5, 1125-1156, doi:10.5194/acp-5-1125-2005, 2005.

Stohl, A., Klimont, Z., Eckhardt, S., Kupiainen, K., Shevchenko, V. P., Kopeikin, V. M., and Novigatsky, A. N.: Black carbon in the Arctic: the underestimated role of gas flaring and residential combustion emissions, Atmos. Chem. Phys., 13, 8833-8855, doi:10.5194/acp-13-8833-2013, 2013.

Stone, E. A., Lough, G. C., Schauer, J. J., Praveen, P., Corrigan, C., and Ramanathan, V.: Understanding the origin of black carbon in the atmospheric brown cloud over the Indian Ocean, J. Geophys. Res.-Atmos., 112, D22S23, doi:10.1029/2006JD008118, 2007.

Stone, E. A., Schauer, J. J., Pradhan, B. B., Dangol, P. M., Habib, G., Venkataraman, C., and Ramanathan, V.: Characterization of emissions from South Asian biofuels and application to source apportionment of carbonaceous aerosol in the Himalayas, J. Geophys. Res.-Atmos., 115, D06301, doi:10.1029/2009JD011881, 2010.

Stone, E. A., Yoon, S.-C., and Schauer, J. J.: Chemical characterization of fine and coarse particles in Gosan, Korea during springtime dust events, Aerosol Air Qual. Res., 11, 31-43, 2011.

Tiitta, P., Vakkari, V., Croteau, P., Beukes, J. P., van Zyl, P. G., Josipovic, M., Venter, A. D., Jaars, K., Pienaar, J. J., Ng, N. L., Canagaratna, M. R., Jayne, J. T., Kerminen, V.-M., Kokkola, H., Kulmala, M., Laaksonen, A., Worsnop, D. R., and Laakso, L.: Chemical composition, main sources and temporal variability of $\mathrm{PM}_{1}$ aerosols in southern African grassland, Atmos. Chem. Phys., 14, 1909-1927, doi:10.5194/acp-14-1909-2014, 2014.

Tuomisto, J. T., Wilson, A., Evans, J. S., and Tainio, M.: Uncertainty in mortality response to airborne fine particulate matter: Combining European air pollution experts, Reliabil. Eng. Syst. Saf., 93, 732-744, 2008.

UNEP: Near-term Climate Protection and Clean Air Benefits: Actions for Controlling Short-Lived Climate Forcers, United Nations Environment Programme (UNEP), Nairobi, Kenya, 78 pp., 2011.

Unger, N., Bond, T. C., Wang, J. S., Koch, D. M., Menon, S., Shindell, D. T., and Bauer, S.: Attribution of climate forcing to economic sectors, P. Natl. Acad. Sci. USA, 107, 3382-3387, 2010.

Vakkari, V., Beukes, J. P., Laakso, H., Mabaso, D., Pienaar, J. J., Kulmala, M., and Laakso, L.: Long-term observations of aerosol size distributions in semi-clean and polluted savannah in South Africa, Atmos. Chem. Phys., 13, 1751-1770, doi:10.5194/acp13-1751-2013, 2013

van der Werf, G. R., Randerson, J. T., Collatz, G. J., Giglio, L., Kasibhatla, P. S., Arellano, A. F., Olsen, S. C., and Kasischke, E. S.: Continental-scale partitioning of fire emissions during the 1997 to $2001 \mathrm{El}$ Nino/La Nina period, Science, 303, 73-76, 2004.
Venkataraman, C. and Rao, G. U. M.: Emission factors of carbon monoxide and size-resolved aerosols from biofuel combustion, Environ. Sci. Technol., 35, 2100-2107, 2001.

Venkataraman, C., Habib, G., Eiguren-Fernandez, A., Miguel, A., and Friedlander, S.: Residential biofuels in South Asia: carbonaceous aerosol emissions and climate impacts, Science, 307, 1454-1456, 2005.

Venter, A. D., Vakkari, V., Beukes, J. P., Van Zyl, P. G., Laakso, H., Mabaso, D., Tiitta, P., Josipovic, M., Kulmala, M., and Pienaar, J. J.: An air quality assessment in the industrialised western Bushveld Igneous Complex, South Africa, S. Afr. J. Sci., 108, 1-10, 2012.

Wang, R., Tao, S., Balkanski, Y., Ciais, P., Boucher, O., Liu, J., Piao, S., Shen, H., Vuolo, M. R., and Valari, M.: Exposure to ambient black carbon derived from a unique inventory and high-resolution model, P. Natl. Acad. Sci. USA, 111, 24592463, 2014.

Wang, X., Wang, Y., Hao, J., Kondo, Y., Irwin, M., Munger, J. W., and Zhao, Y.: Top-down estimate of China's black carbon emissions using surface observations: sensitivity to observation representativeness and transport model error, J. Geophys. Res.Atmos., 118, 5781-5795, 2013.

Wang, X., Heald, C. L., Ridley, D. A., Schwarz, J. P., Spackman, J. R., Perring, A. E., Coe, H., Liu, D., and Clarke, A. D.: Exploiting simultaneous observational constraints on mass and absorption to estimate the global direct radiative forcing of black carbon and brown carbon, Atmos. Chem. Phys., 14, 10989-11010, doi:10.5194/acp-14-10989-2014, 2014.

WHO: The Energy Access Situation in Developing Countries, World Health Organization and United Nations Development Programme, New York, USA, 2009.

WHO: Burden of Disease from Household Air Pollution for 2012, World Health Organisation, Geneva, Switzerland, 2014a.

WHO: Burden of Disease from Ambient Air pollution for 2012, World Health Organisation, Geneva, Switzerland, 2014b.

Xu, B., Cao, J., Hansen, J., Yao, T., Joswia, D. R., Wang, N., Wu, G., Wang, M., Zhao, H., and Yang, W.: Black soot and the survival of Tibetan glaciers, P. Natl. Acad. Sci. USA, 106, 22114-22118, 2009.

Yu, S., Eder, B., Dennis, R., Chu, S. H., and Schwartz, S. E.: New unbiased symmetric metrics for evaluation of air quality models, Atmos. Sci. Lett., 7, 26-34, 2006.

Zhang, X., Wang, Y., Zhang, X., Guo, W., and Gong, S.: Carbonaceous aerosol composition over various regions of China during 2006, J. Geophys. Res.-Atmos., 113, D14111, doi:10.1029/2007JD009525, 2008.

Zhi, G., Chen, Y., Feng, Y., Xiong, S., Li, J., Zhang, G., Sheng, G., and Fu, J.: Emission characteristics of carbonaceous particles from various residential coal-stoves in China, Environ. Sci. Technol., 42, 3310-3315, 2008. 